Research Article

\title{
Geospatial Multicriteria Analysis for Earthquake Risk Assessment: Case Study of Fujairah City in the UAE
}

\author{
Diena Al-Dogom, ${ }^{1}$ Rami Al-Ruzouq ${ }^{D},{ }^{2}$ Bahareh Kalantar $\left(\mathbb{D},{ }^{3}\right.$ Karen Schuckman, 4 \\ Saeed Al-Mansoori, ${ }^{5}$ Sunanda Mukherjee, ${ }^{2}$ Hussain Al-Ahmad, ${ }^{1}$ and Naonori Ueda ${ }^{3}$ \\ ${ }^{1}$ College of Engineering and Information Technology, University of Dubai, UAE \\ ${ }^{2}$ Department of Civil and Environmental Engineering, University of Sharjah, 27272 Sharjah, UAE \\ ${ }^{3}$ RIKEN Centre for Advanced Intelligence Project, Goal-Oriented Technology Research Group, Disaster Resilience Science Team, \\ Tokyo 103-0027, Japan \\ ${ }^{4}$ Department of Geography, The Pennsylvania State University, USA \\ ${ }^{5}$ Applications Development and Analysis Centre, Mohammed Bin Rashid Space Centre, UAE
}

Correspondence should be addressed to Rami Al-Ruzouq; ralruzouq@sharjah.ac.ae and Bahareh Kalantar; bahareh.kalantar@riken.jp

Received 18 June 2021; Revised 28 July 2021; Accepted 18 August 2021; Published 26 September 2021

Academic Editor: Carmine Granata

Copyright (c) 2021 Diena Al-Dogom et al. This is an open access article distributed under the Creative Commons Attribution License, which permits unrestricted use, distribution, and reproduction in any medium, provided the original work is properly cited.

\begin{abstract}
A clear understanding of the spatial distribution of earthquake events facilitates the prediction of seismicity and vulnerability among researchers in the social, physical, environmental, and demographic aspects. Generally, there are few studies on seismic risk assessment in United Arab Emirates (UAE) within the geographic information system (GIS) platform. Former researches and recent news events have demonstrated that the eastern part of the country experiences jolts of 3-5 magnitude, specifically near Fujairah city and surrounding towns. This study builds on previous research on the seismic hazard that extracted the eastern part of the UAE as the most hazard-prone zone. Therefore, this study develops an integrated analytical hierarchical process (AHP) and machine learning (ML) for risk mapping considering eight geospatial parameters-distance from shoreline, schools, hospitals, roads, residences, streams, confined area, and confined area slope. Experts' opinions and literature reviews were the basis of the AHP ranking and weighting system. To validate the AHP system, support vector machine (SVM), decision tree (DT), and random forest (RF) classifiers were applied to the datasets. The datasets were split into $60: 40$ ratio for training and testing. Results show that SVM has the highest accuracy of $79.6 \%$ compared to DT and RF with a "predicted high" precision of $87.5 \%$ attained from the model. Risk maps from both AHP and ML approaches were developed and compared. Risk analysis was categorised into 5 classes "very high," "high," "moderate," "low," and "very low." Both approaches modelled relatable spatial patterns as risk-prone zones. AHP approach concluded $3.6 \%$ as "very high" risk zone, whereas only $0.3 \%$ of total area was identified from ML. The total area for the "very high" $\left(20 \mathrm{~km}^{2}\right)$ and "high" $\left(114 \mathrm{~km}^{2}\right)$ risk was estimated from ML approach.
\end{abstract}

\section{Introduction}

Earthquakes are considered short-term calamities that exert a significant long-term impact on human lives, infrastructure, and the economy that can last for decades or longer $[1,2]$. The severity of a tremor can range from light, i.e., nearly no impact, to sufficiently strong to destroy means of livelihood [3]. Tremors are defined on the basis of their epicenter's geo- graphic location, magnitude, frequency, duration, and onset speed. The seismic actions are measured based on an earthquake's frequency and magnitude occurring within a certain period. These hazards contribute to severe vulnerability in terms of loss of human life, society, and economy. The vulnerability of built-up areas to earthquakes and other natural hazards is a consequence of construction methodology and the quality of materials [4]. 
The United Arab Emirates (UAE) experiences low seismic activities, and their hazards [5] are categorised as insignificant by various researchers [6]. With the country's growing population, dramatic infrastructure development has occurred over the last 30 years. Numerous studies have indicated that the UAE lies in low-seismicity zones, and no massive fatalities from earthquakes have been reported yet. However, in the recent few years, the country experienced earthquake jolts that were primarily concentrated in its eastern part, i.e., the Fujairah Emirate [7]. The UAE has designed infrastructure codes to manage any anticipated earthquake efficiently [8-11]. Few studies have been carried on earthquake risk management for the country within the geospatial platform. Therefore, it is crucial to analyse the earthquake risk within the country to elude any havoc for future mitigation. This research focuses on developing a technique to ascertain most risk-prone zones in the Fujairah city and surrounding towns in UAE.

Generally, seismicity and vulnerability hazard assessments are conducted by traditional theoretical and empirical algorithms and conventional decision-making processes based on earthquake magnitude and intensity. However, over recent years, remote sensing (RS), geographic information system (GIS), and machine learning (ML) techniques are evolving for earthquake risk assessment. Geotechnical, structural, and social-economic are some of the key points to investigate the earthquake [3, 12-14]. Many studies [15-27] have combined spatial statistical techniques and the analytical hierarchy process (AHP) integrated with a GIS to investigate seismic hazards, vulnerability, and their associated risks to humans and the environment.

A contemporary study [28] on earthquake risk assessment has been carried in northeast India. The study focussed on distance from railway, railway density, distance from landuse, landuse density, distance from buildings, and building geospatial density layers. These layers were integrated with AHP [29, 30] and convolutional neural network (CNN) to microzonate risk. Three major regions were identified to be likely experiencing higher intensity events and therefore is more risk prone in the southern part of the state. Model developed utilizing CNN showed an accuracy of 0.94 and a precision of 0.98. Another novel research [31] assessed seismic vulnerability in Tehran, Iran. The factors such as peak ground acceleration (PGA), slope, construction (material, quality), population, employment status, open spaces, road network, fire stations, hospitals, gas pipes, and gasoline stations were integrated into radial basis function (RBF) and teaching-learning-based optimization (TLBO) to optimize weights of each factor. Their findings reflected that PGA has a higher liquefaction probability, therefore, higher seismic vulnerability in the region. A contemporary study [3] utilized the population data, anticipated seismic events, infrastructure aggregate, elevation, and earthquake hazard events of the UAE and then integrated AHP to analyse the hazard's adversity. This study reported that the northern part of the UAE is more hazard-prone and vulnerable than its southern part. The authors deduced that several infrastructure elements only have a minimal degree of protection from seismic activities, and consequently, the seismic design practice is still in its nascent stages in the UAE. We investigated the most commonly used factors and techniques in the literature (Table 1). The following parameters are most utilized for seismicity: PGA, soil type, geology, distance from active faults, epicenter, and slope. Whereas for vulnerability, the most utilized parameters are a distance from residences, hospitals, streams, roads, landuse, landuse density, and topography.

This research utilized AHP supported by ML techniques to zonate seismic vulnerability for Fujairah City and surrounding towns in UAE. Towards generating the seismic hazard map five parameters such as PGA, fault distances, slope, soil, and geology were considered. To analyse the vulnerability, eight parameters such as distances from the shoreline, schools, hospitals, roads, residences, confined areas, streams, and slope were considered. The generated seismic hazard map was then multiplied with vulnerability map to adopt the risk map finally. The primary objectives of the current study can be summarised as follows: (i) investigate risk-prone zones for disaster management within UAE; (ii) analyse the seismicity in the UAE; (iii) identify and map topography, hydrology, and distance from residences, streams, and other parameters for earthquake risk assessment; (iv) employ and compare AHP and ML techniques for preparing a risk map of Fujairah City and its surrounding towns.

The following section provides a brief explanation of the study area. Thereafter, a case study of the UAE is presented to understand the high seismic-prone zones. The subsequent section analyses factors and techniques related to risk assessment from AHP and ML point of view. After the results are provided, the paper summarizes the study's significant findings and provides suggestions for future research.

\section{Study Area}

The UAE is located in the eastern part of the Arabian Peninsula, and it shares its borders with Saudi Arabia in the southwest and Oman in the East. It sits on the eastern part of the Arabian Plate (Figure 1), close to the collision zone of the Arabian and Eurasian Plates. Topographically, the country is covered with $95 \%$ plains, mostly constituted by desert, with 5\% mountainous regions. The Hajjar Mountains are located in the eastern part of the country, where elevation rises up to $2000 \mathrm{~m}$.

Rugged terrains mostly cover eastern Emirates, such as Fujairah and Ras-al Khaimah. With an area of $1450 \mathrm{~km}^{2}$, Fujairah is the fifth largest Emirate. It is situated in the eastern part of the UAE, bordering the Gulf of Oman. The Fujairah Emirate has been the most seismically active region in the UAE, having experienced tremors of magnitude 5 in March 2002 and magnitude 2.2 in September 2011 in the Masafi region $[3,13,36]$. The Al Dibba region also recorded tremors in November 2009 [13, 36, 37]. Although these incidents did not lead to any casualties, researchers are focusing on the risk assessment of the region due to the rapid pace of urbanisation. Primary risk assessment is narrowed down to the eastern part of the Fujairah Emirate, covering the densely populated cities of Fujairah, Kalba, Al Aqdah, Hail, Al 
TABLE 1: Review of recent seismic vulnerability assessment studies.

\begin{tabular}{|c|c|c|c|}
\hline References & Study area & Utilized parameters & Utilized techniques \\
\hline $\begin{array}{l}\text { Jena et al. } 2021 \\
\text { [28] }\end{array}$ & $\begin{array}{l}\text { Northeast, } \\
\text { India }\end{array}$ & $\begin{array}{l}\text { Distance from railway, railway density, distance from landuse, } \\
\text { landuse density, distance from buildings, and building density }\end{array}$ & $\begin{array}{l}\text { Analytical hierarchy process (AHP) } \\
\text { and convolutional neural network } \\
\text { (CNN) }\end{array}$ \\
\hline $\begin{array}{l}\text { Yariyan et al. } \\
2020[4]\end{array}$ & $\begin{array}{l}\text { Sanandaj } \\
\text { City, Iran }\end{array}$ & $\begin{array}{c}\text { Building materials, landuse, distance from hospital, distance from } \\
\text { fire station, number of floors, distance from street, altitude, } \\
\text { lithology, distance from the fault, slope, distance from the stream, } \\
\text { and population density }\end{array}$ & $\begin{array}{l}\text { Fuzzy-multiple criteria analysis } \\
\text { (fuzzy-MCDA) and logistic regression }\end{array}$ \\
\hline $\begin{array}{l}\text { Lee et al. } 2019 \\
\text { [31] }\end{array}$ & $\begin{array}{l}\text { Tehran, } \\
\text { Iran }\end{array}$ & $\begin{array}{l}\text { Peak ground acceleration (PGA), slope, construction (material, } \\
\text { quality), population, employment status, open spaces, road } \\
\text { network, fire stations, hospitals, gas pipes, and gasoline stations }\end{array}$ & $\begin{array}{l}\text { Radial basis function (RBF) and } \\
\text { teaching-learning-based optimization } \\
\text { (TLBO) }\end{array}$ \\
\hline $\begin{array}{l}\text { Jena et al. } 2019 \\
\text { [32] }\end{array}$ & $\begin{array}{l}\text { Banda } \\
\text { Aceh, } \\
\text { Indonesia }\end{array}$ & $\begin{array}{l}\text { Slope, curvature, elevation, aspect, epicenter density, epicenter } \\
\text { distance, depth density, magnitude distribution, PGA density, } \\
\text { fault, building density, office, population, and transport nodes }\end{array}$ & $\begin{array}{l}\text { Artificial neural network (ANN) and } \\
\text { AHP }\end{array}$ \\
\hline $\begin{array}{l}\text { Liu et al. } 2019 \\
\text { [33] }\end{array}$ & $\begin{array}{l}\text { Urumqi, } \\
\text { China }\end{array}$ & $\begin{array}{c}\text { Type of structure, period of construction, number of floors, land } \\
\text { use and land cover, and roof type }\end{array}$ & $\begin{array}{l}\text { SVM and association rule learning } \\
\text { (ARL) }\end{array}$ \\
\hline $\begin{array}{l}\text { Hopkins and } \\
\text { Turan et al. } 2018 \\
{[34]}\end{array}$ & Turkey & $\begin{array}{l}\text { Topography, source to site distance, soil classification, liquefaction } \\
\text { potential, and fault mechanism }\end{array}$ & $\begin{array}{l}\text { AHP, technique for order preference } \\
\text { by similarity to ideal solution } \\
\text { (TOPSIS) }\end{array}$ \\
\hline $\begin{array}{l}\text { Ahmad et al. } \\
2017[35]\end{array}$ & Syria & $\begin{array}{c}\text { PGA, earthquake epicentres, active faults, digital elevation model, } \\
\text { and slope }\end{array}$ & Earthquake potential index (EPI) \\
\hline
\end{tabular}

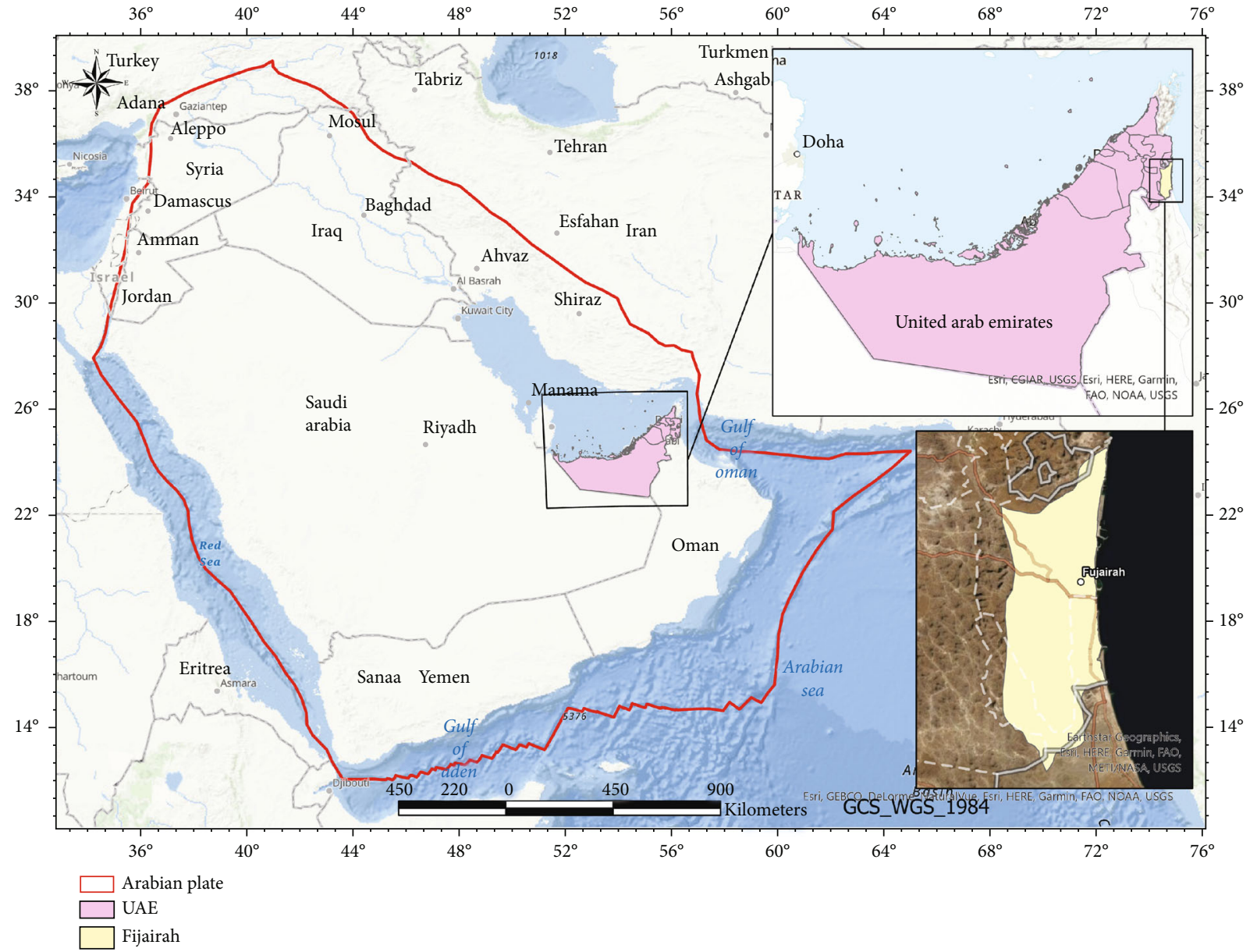

FIgURE 1: Location map of the study area. 
Bithnah, and Qurayya, which are regions near the seashore. These cities lie in an area which is bounded between mountains and sea as shown in Figure 2(b) and 2(c). The mountains enclosing Fujairah City and its surrounding areas are generally more than 200 ? $\mathrm{m}$ until 1000 ? $\mathrm{m}$ high.

The current study utilized historical earthquake data to determine the risk-prone zones in UAE. An earthquake catalogue that contains the date, time, latitude, longitude, and magnitude was used as reference; it covers 13,156 events from 1900 to 2015 [36, 38]. It includes the entire Arabian Plate and its neighbouring territories, i.e., every significant hazard for the Arabian Plate [38, 39]. Table 2 lists historical earthquake events and some of their associated attributes [38].

\section{Methodology}

Figure 3 represents the methodology of this study. The study has been constructed into two parts: (a) seismic analysis of UAE using AHP and demarcating the seismic prone zone based on historic earthquake events, (b) risk analysis for the most hazard-prone zone within UAE. Soil, geology, distance from faults, slope (percent), and PGA parameters were paired with AHP and weighted overlay in ArcGIS Pro to zonate seismic prone regions in UAE. Investigation of earthquake risk assessment was supported consuming parameters such as in situ data of built-up areas, roads network, hospitals, schools, ocean shoreline, and digital terrain model (DTM) were processed to attain a required thematic layer of each parameter, respectively, in the GIS framework. Then, integration of AHP and ML models (support vector machine (SVM), decision tree (DT), and random forest (RF)) paired with weighted overlay facilitated obtaining a risk map. Intensive literature review and expert opinion were the basis for weights and ranks. Pairwise comparison matrix validated the weights of each parameter in the AHP technique. 500 random points were generated and processed in ML platforms as 60 to 40 ratio training and testing datasets. The ML model helped to modify the weights of each criterion. Weighted overlay was applied to develop the risk map.

3.1. Assessment of Seismic Prone Zones of UAE. This section describes the geospatial thematic layers utilized to demarcate seismic-prone zones of UAE paired with AHP technique in GIS environment. Also, to validate the AHP technique, a pairwise comparison matrix was also developed.

3.1.1. Geospatial Parameters for Hazard Assessment. Five thematic layers, namely, PGA, soil classification, distance from fault, slope percentage, and geology, were considered in seismic hazard-prone zonation. Each layer exhibits a correlation with earthquake hazard. PGA is the maximum ground acceleration observed during an earthquake. Previous earthquake seismicity research $[9,40]$ observed a decline in PGA as distance increases from the epicenter. In the current research, given that no major seismograph events occurred in the UAE, ground acceleration was calculated using the ground motion prediction equation that considers all the historical earthquake events in the entire Arabian
TABLE 2: Sample of an earthquake catalogue [38].

\begin{tabular}{lcccc}
\hline $\begin{array}{l}\text { Date M/ } \\
\text { D/Y }\end{array}$ & Time & $\begin{array}{c}\text { Latitude } \\
\text { Dego }\end{array}$ & $\begin{array}{c}\text { Longitude } \\
\text { Dego }\end{array}$ & $\begin{array}{c}\text { Magnitude } \\
\text { Mw }\end{array}$ \\
\hline $1 / 5 / 1900$ & $0: 55: 00$ & 34.45 & 34.00 & 6.1 \\
$1 / 18 / 1900$ & $5: 29: 00$ & 29.00 & 33.00 & 4.6 \\
$1 / 27 / 1900$ & $2: 30: 00$ & 37.63 & 37.37 & 5.3 \\
$2 / 24 / 1900$ & $0: 30: 00$ & 38.45 & 44.87 & 5.6 \\
$3 / 6 / 1900$ & $17: 58: 00$ & 29.00 & 33.00 & 6.5 \\
$1 / 5 / 1900$ & $0: 55: 00$ & 34.45 & 34.00 & 6.1 \\
\hline
\end{tabular}

Plate from previous researches [36, 41]. As stated in [12], only two major faults exert a direct seismicity effect on the UAE: the Zagros Fold [14] and the thrust belt in Makran zone $[3,11]$. In this study, PGA has been established employing attenuation relation by the following equation $[41,42]$.

$$
\log A=C_{1} M_{w}+C_{2} R-C_{3} \log R+C_{i} S_{i}+(\sigma) P, \mathrm{i}=1,2,3,
$$

where $A$ is PGA $\mathrm{cm} / \mathrm{sec}^{2} ; M$ is earthquake magnitude moment; $R$ is hotspot distance (km); $C_{1}(.399), C_{2}(-.0019)$, and $C_{3}$ (1) are constants of Zagros horizontal component used for this study; $C_{i}$ is site class; $S_{i}$ is site condition; $\sigma$ is standard deviation; and $P$ is constant $(0,1)$.

The thematic layer of distance from faults exhibits an inverse relationship with seismicity. Fault lines were extracted from Landsat 8 satellite images of 30 meters spatial resolution, and then, the Euclidean distance was calculated. Near distances of up to $200 \mathrm{~km}$ from fault lines were considered the most seismic prone [41]. The soil layer comprises torripasmments, calciorthids, saliorthids, torrifluvents, gypsiorthids torriorthents, and salorthids. Torripasmments being clay rich is not at risk for seismicity [36], whereas saliorthids, calciorthids, and torrifluvents are more seismically prone in the UAE than the other soil classes [3, 41]. A slope spatial map was derived from the (Advanced Spaceborne Thermal Emission and Reflection Radiometer) ASTER digital elevation model (DEM) with a resolution of $3 \mathrm{~m}$. Although most of the land shares similar slopes, higher steep slopes are found in the north-eastern part of UAE. Therefore, slopes with $>30^{\circ}$ were considered under higher seismic zones [36]. The geology thematic layer was prepared from Landsat 8 satellite images by applying supervised classification. The layers contain sand, alluvium, limestone, metamorphic rocks, gabbro, and ophiolite. Sand has the least compactness, and thus, it was considered the most seismic prone [36]. Literature review and experts' opinion were the basis of weights for all seismic hazard parameters (Table 3). Weights and ranks were validated using the AHP technique by preparing a pairwise comparison matrix. AHP is discussed in the next section.

3.1.2. AHP for Hazard Assessment. Each parameter was evaluated using Saaty's AHP [18, 24, 34, 41], [43]. Saaty's AHP is a decision-making procedure based on each criterion and 


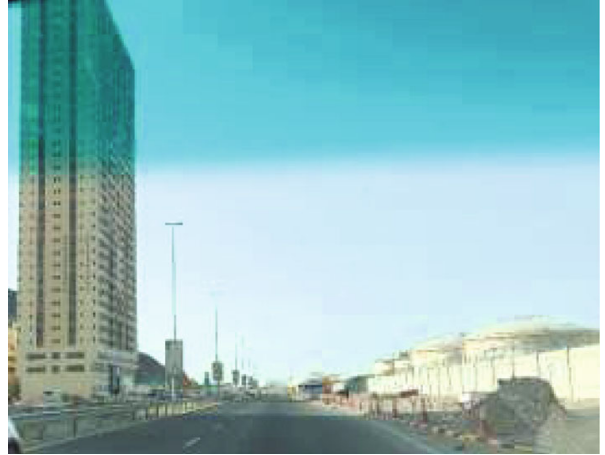

(a)

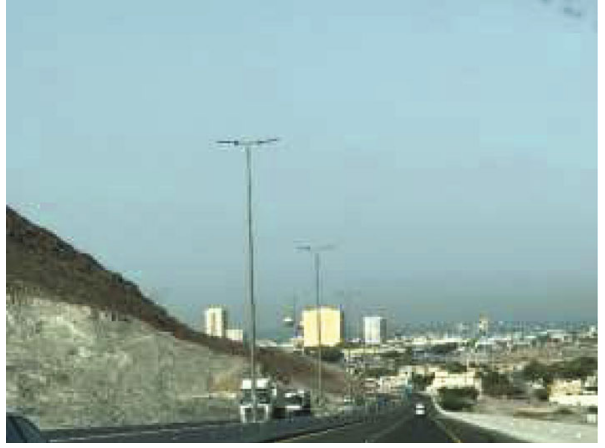

(c)

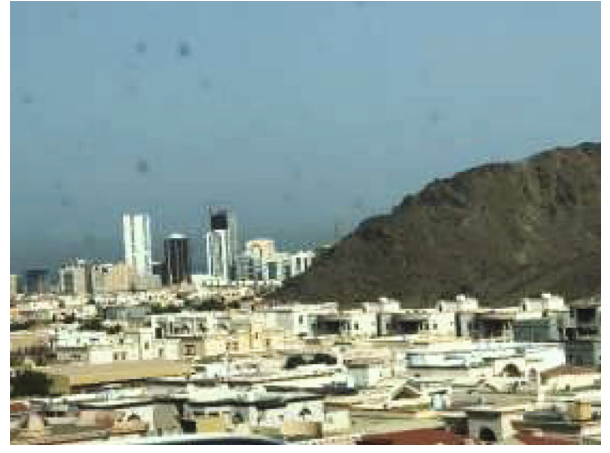

(b)

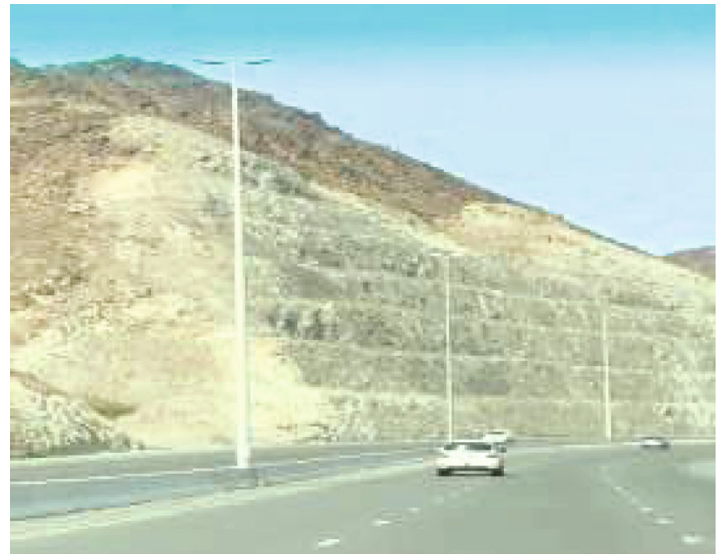

(d)

Figure 2: Physical images of Fujairah City. (a) Oil storage tanks in close proximity to residential buildings. (b) Residences near mountains. (c) Settlements near seashore. (d) Unpaved rock elements besides roads.

alternatives [44]. The parameters were assigned with weights in accordance with the rank of their suitability and importance. The AHP technique consists of three major steps [45]. In the initial step, the decision-making problem was divided into a hierarchical structure that consists of all the parameters. Several factors were utilized to create a hierarchy of the primary goal of identifying hazard-prone areas. The next step was to establish decision tables for each hierarchy level. The matrices denoted pairwise comparisons (PC-matrices) by using comparable data. A nine-point scale was used for comparison, or alternatively, actual data can also be used if available [24]. The nine-point scale includes $9,8,7, \ldots, 1 / 7,1 / 8,1 / 9$, where 9 indicates extreme preference, 7 indicates very strong preference, 5 indicates strong preference, and so on down to 1 , which means no preference. An independent evaluation of each factor's contribution was made due to the pairwise comparison, which helped simplify the decision-making process [18]. The pairwise comparisons were arranged in a square matrix, with the diagonal elements being 1 . The relative importance of the criteria was determined by calculating the principal eigenvalue and the corresponding normalized right eigenvector of the comparison matrix. The elements of the normalized eigenvector were weighted with reference to the criteria or subcriteria and rated with respect to the alternatives [18]. Then, an evaluation of the consistency of the matrix of order was performed on the basis of Equations (2)-(4) [41, 43].

$$
\begin{gathered}
\mathrm{CI}=\frac{\lambda_{\max }-n}{n-1}, \\
\mathrm{RI}=\frac{1.98(n-1)}{n}, \\
\mathrm{CR}=\frac{\mathrm{CI}}{\mathrm{RI}},
\end{gathered}
$$

where $\mathrm{CI}$ is the consistency index, RI is the randomised index, CR is the consistency ratio, and $n$ is the order of the compression matrix.

Pairwise comparison matrix was utilized to validate the weights of the parameters (Table 4). To validate the consistency of the model, CR should be $<10 \%$ [18]. The CR of this model was calculated as $3 \%$, validating the ranking and weighting criteria as true. After validating the ranking technique, the weights were assigned in ArcGIS by utilizing the weighted overlay tool to prepare the output. The seismic hazard map of the UAE was reclassified into five zones: very high, high, moderate, low, and very low (Figure 4) [38].

From the analysis of Figure 4, the very high hazard zone is clearly found in Fujairah City, a highly populated region with an area of $202 \mathrm{~km}^{2}$. Approximately $11 \%$ of the UAE, including areas within Fujairah, Ras Al Khaimah, and 


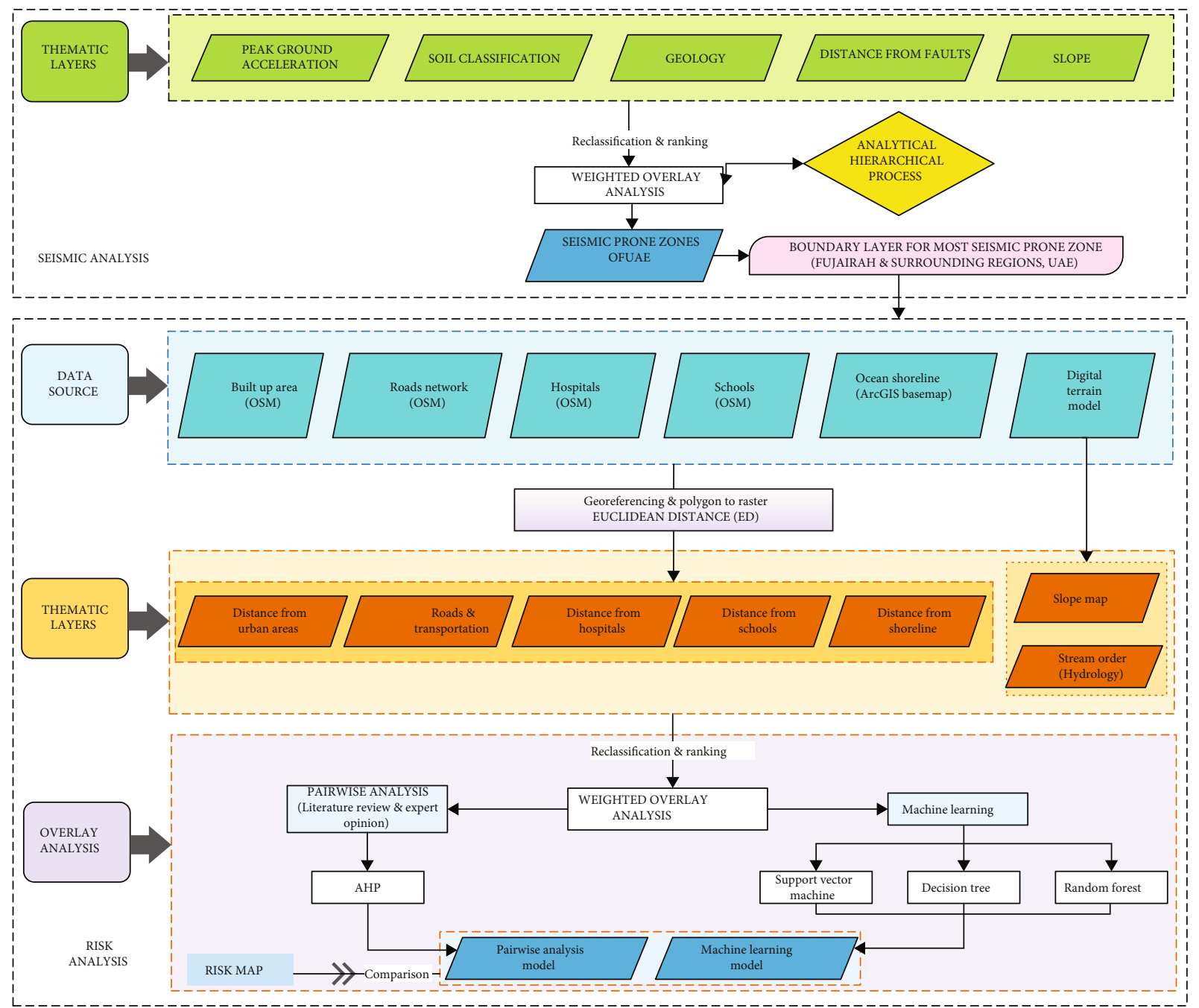

Figure 3: Methodology framework of the study.

TABLE 3: Weight criteria for the parameters.

\begin{tabular}{lc}
\hline Thematic layers & Weights \\
\hline Peak ground acceleration & $30 \%$ \\
Distance from faults & $30 \%$ \\
Slope percent & $5 \%$ \\
Soil class & $15 \%$ \\
Geology & $20 \%$ \\
\hline
\end{tabular}

Sharjah, fell within a high hazard zone. Sharjah and Dubai lie from high to moderate zones, whereas Abu Dhabi is located considerably far from seismic hotspots and lies within the low seismic hazard zone. In the long term, risk analysis, contingency strategies, land use action plans, and relief measures should be considered and promoted in these areas for critical disaster management.

3.2. Risk Assessment of Fujairah City and Neighbouring Areas. This section describes the vulnerability and riskprone zones of Fujairah City and its adjacent towns, the associated factors, and techniques. Finally, the risk map is developed using AHP and the weighted overlay, and also ML techniques have been employed to understand the parameters for the risk associated with earthquake hazard.

3.2.1. Vulnerability Assessment of Fujairah City. Vulnerability is the possible impact of a particular hazard on a community and its environment $[46,47]$. It is included within the risk framework. Following the United Nations (UN) (2004), risk has two major components. The first component is the hazard itself, the damaging event, human activity, or phenomenon characterised by location, intensity, frequency, and probability. The second component is vulnerability, which defines the hazard severity's interdependency and its potential degree of damage [46]. The UN (2004) defined risk assessment with the help of Equation (6) [47].

$$
\text { Risk }=\text { Hazard } \times \text { Vulnerability }
$$

Different types of earthquake vulnerability are influenced by the selection and mapping of each criterion, and the study and incorporation of these criteria are considered 
TABLE 4: Pairwise comparison matrix for seismic hazard parameters.

\begin{tabular}{lccccc}
\hline & Peak ground acceleration & Distance from faults & Slope percent & Soil class & Geology \\
\hline Peak ground acceleration & 1 & 1.0 & 6 & 2 & 1.5 \\
Distance from faults & 1.0 & 1 & 6 & 2 & 1.5 \\
Slope percent & 0.17 & 0.17 & 1 & 0.3 & 0.25 \\
Soil class & 0.5 & 0.5 & 3 & 1 & 0.75 \\
Geology & 0.67 & 0.67 & 1.3 & 1.33 & 1 \\
\hline
\end{tabular}

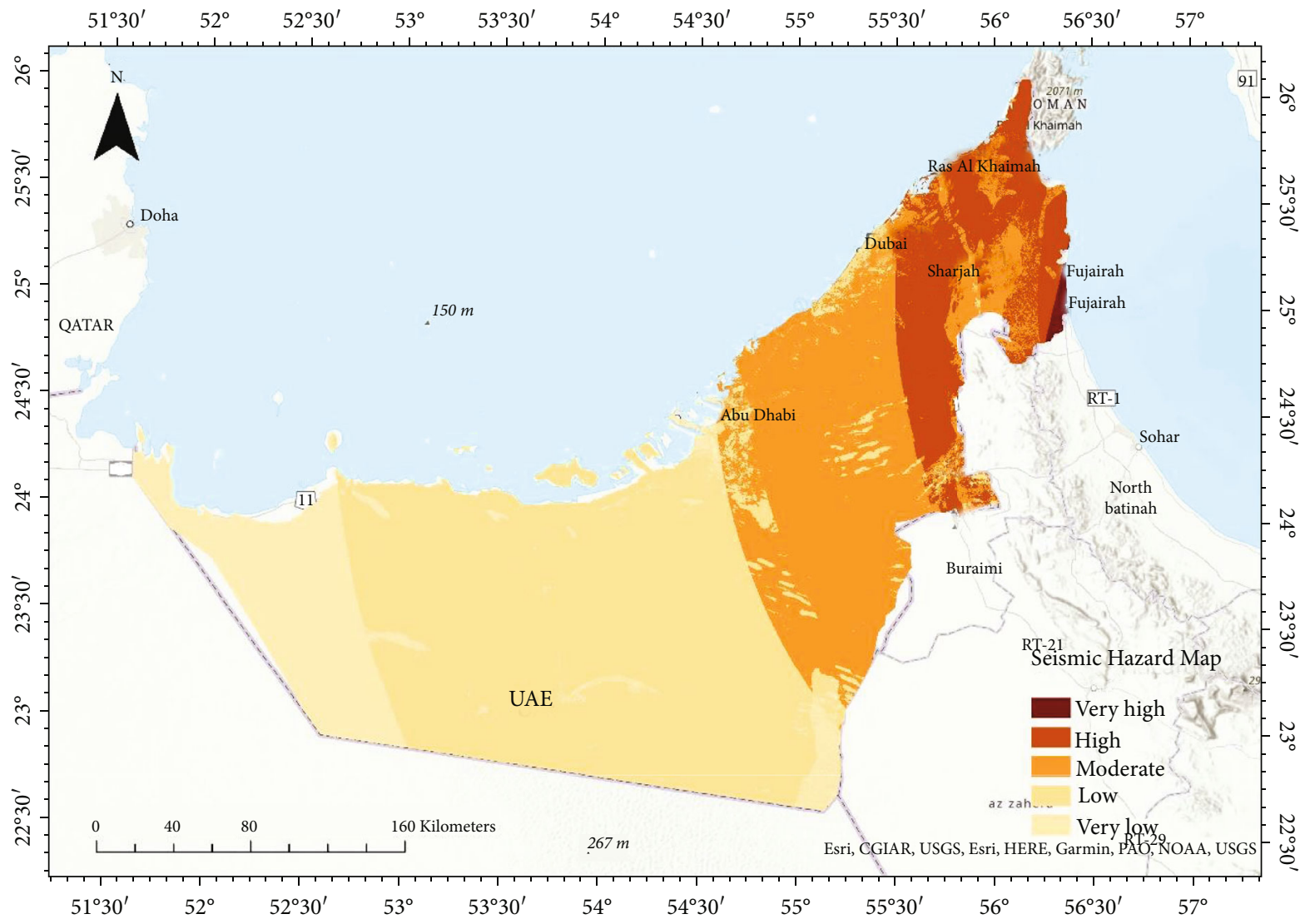

FIGURE 4: Seismic prone zones of the UAE [38].

in an efficient earthquake vulnerability mapping process [ 18 , $26,27,48]$.

3.2.2. Geospatial Parameters for Risk Assessment. The vulnerability of a particular area to earthquakes can be predicted using spatial and temporal components. Spatial layers vary depending on the location, nature, and boundary conditions of different regions [45]. Layers, such as built-up, transportation networks, hospitals, and school locations, were first extracted from OpenStreetMap (OSM) in vector format and then georeferenced. The calculation of the Euclidean distance helps in assessing earthquake vulnerability [4]. DTM downloaded from the website of the United States Geological Survey for the region of Fujairah was used to extract a slope map and a stream order. The shoreline of Fujairah was demarcated using the base map in ArcGIS Pro. Further details of the layers are discussed in the succeeding sections.
(1) Spatial Euclidean Distances. In the current study, Euclidean distances from the shoreline, schools, roads, and hospitals were calculated to determine the hazard's vulnerability.

(i) Shoreline. The vulnerability effect decreases as distance from the shoreline increases [49]. An earthquake of high intensity will likely aggravate the adjacent water body (the Gulf of Oman in this case), leading to higher waves, and eventually, floods or tsunami, affecting close areas. The shoreline was spatially mapped utilizing Landsat 8 images. Euclidean distance was then calculated to obtain the thematic layer as presented in Figure 5(a). The layer was reclassified by assigning the highest ranks to a distance of approximately $3 \mathrm{~km}$ from the shoreline. The degree of vulnerability decreases as the distance from shoreline increases, with the least effect occurring at distances of more than $9 \mathrm{~km}$, and the most 


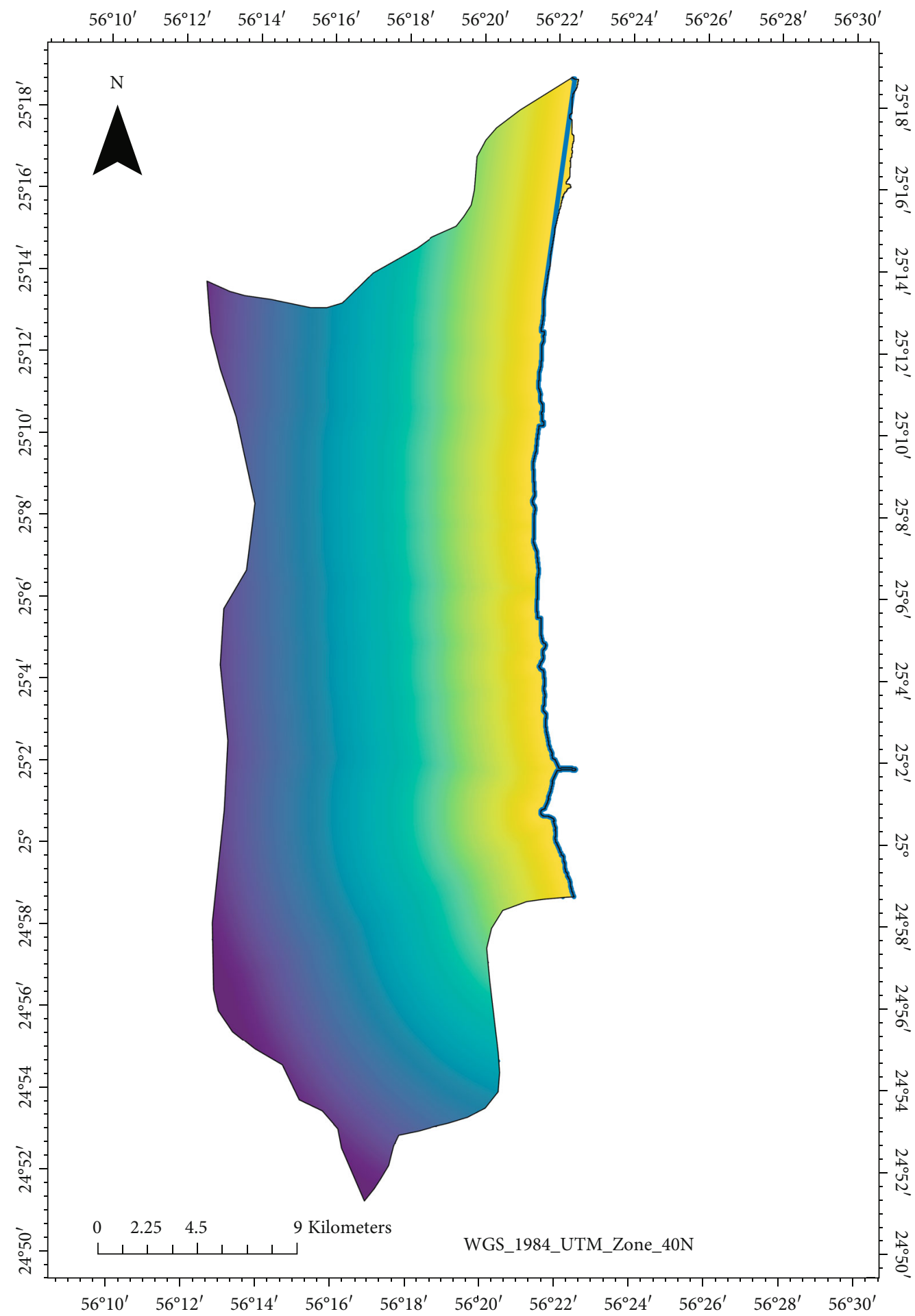

Distance from shoreline (m)

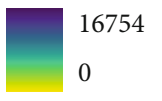

— Shoreline

(a)

Figure 5: Continued. 


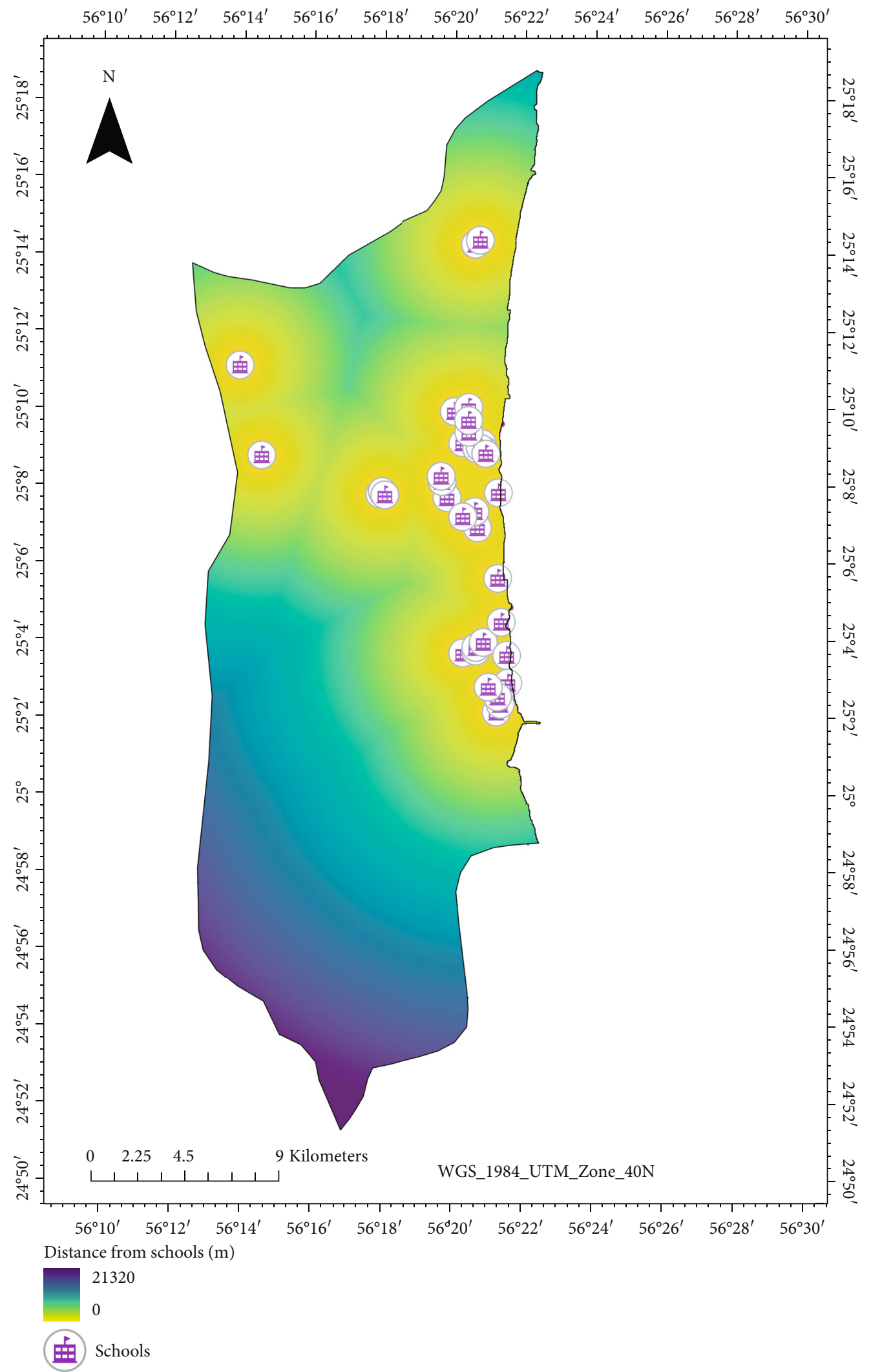

(b)

Figure 5: Continued. 


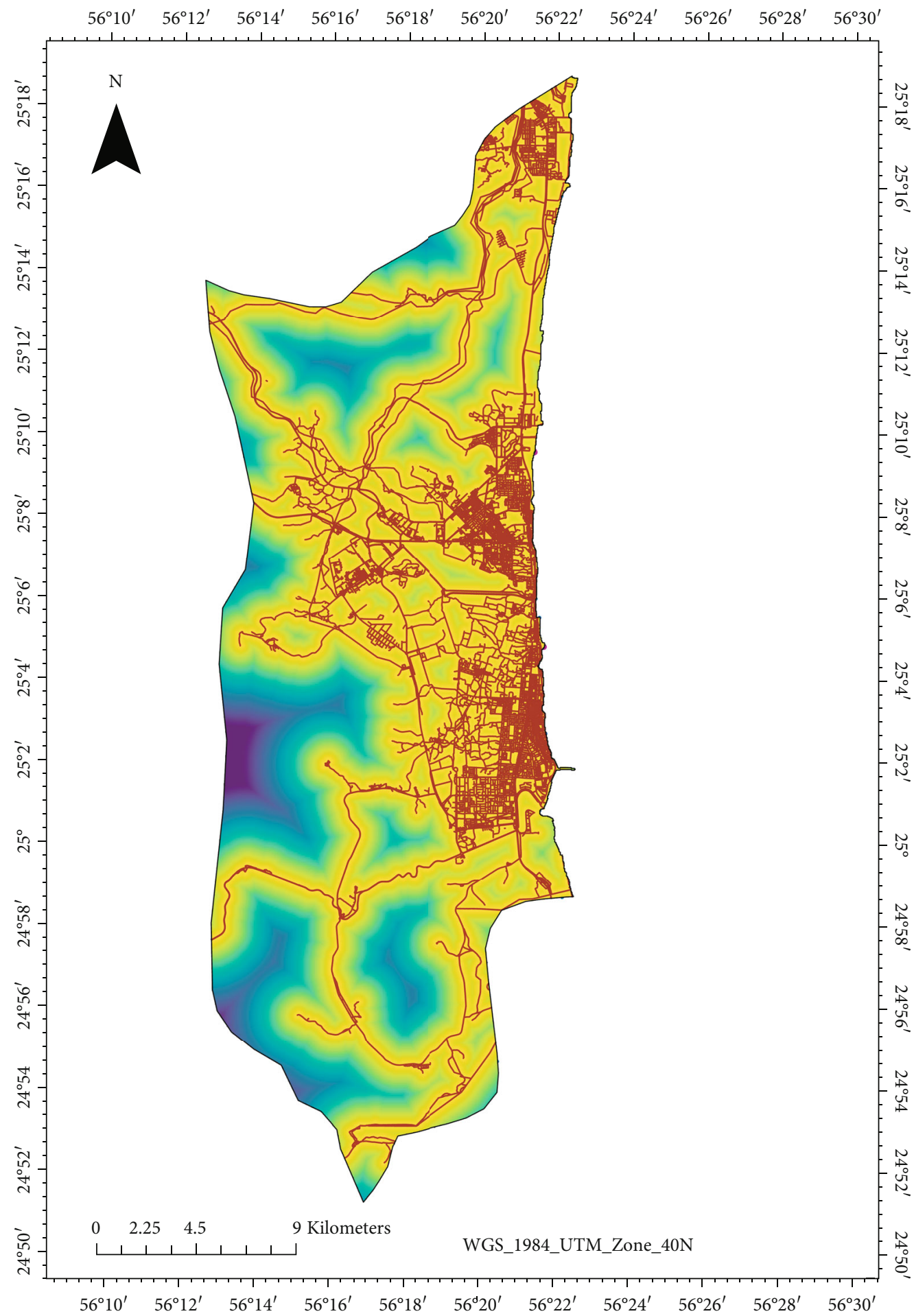

Distance from roads $(\mathrm{m})$

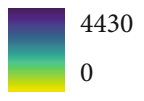

— Roads

(c)

Figure 5: Continued. 


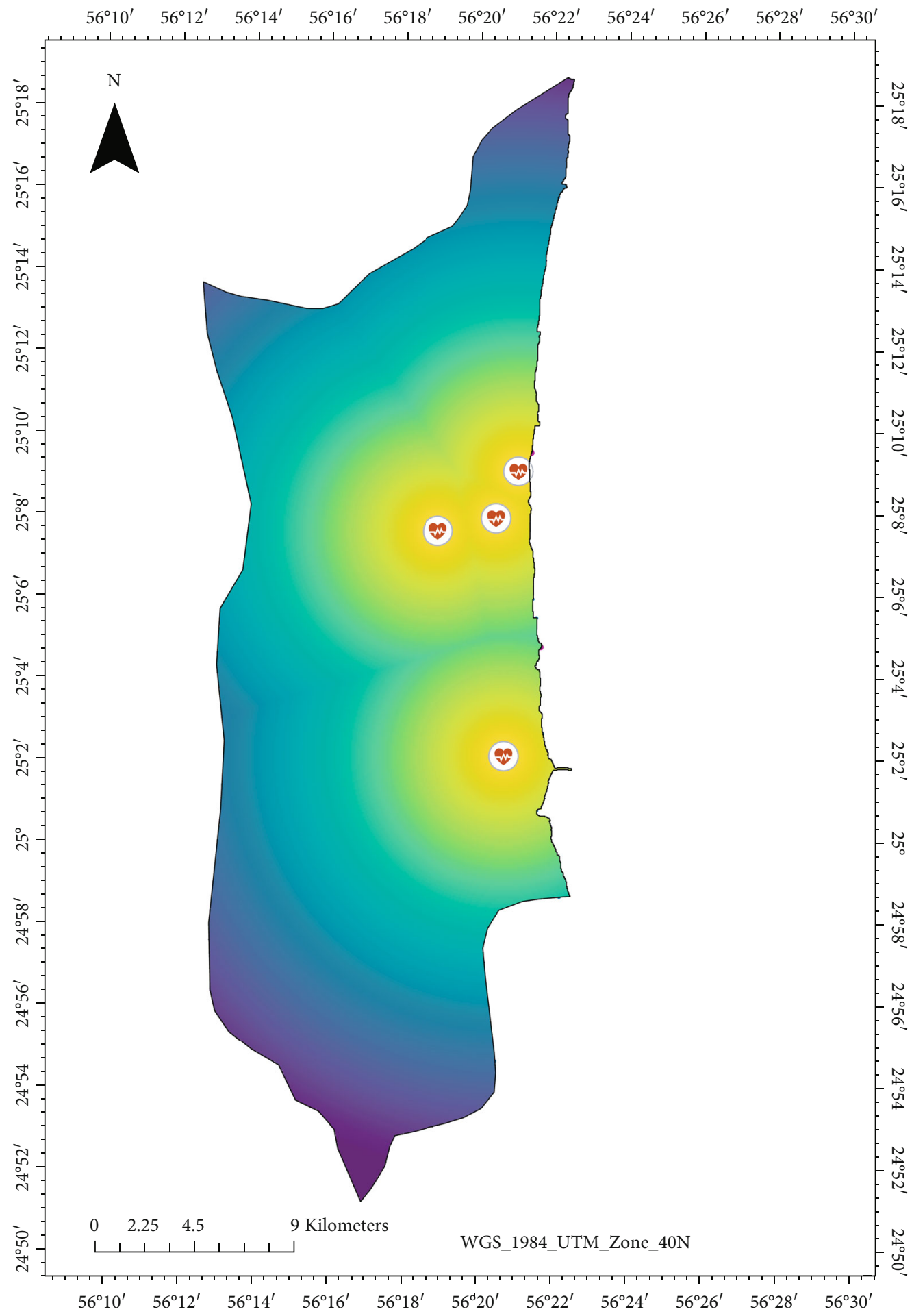

Distance from hospital (m)

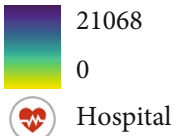

(d)

Figure 5: Continued. 


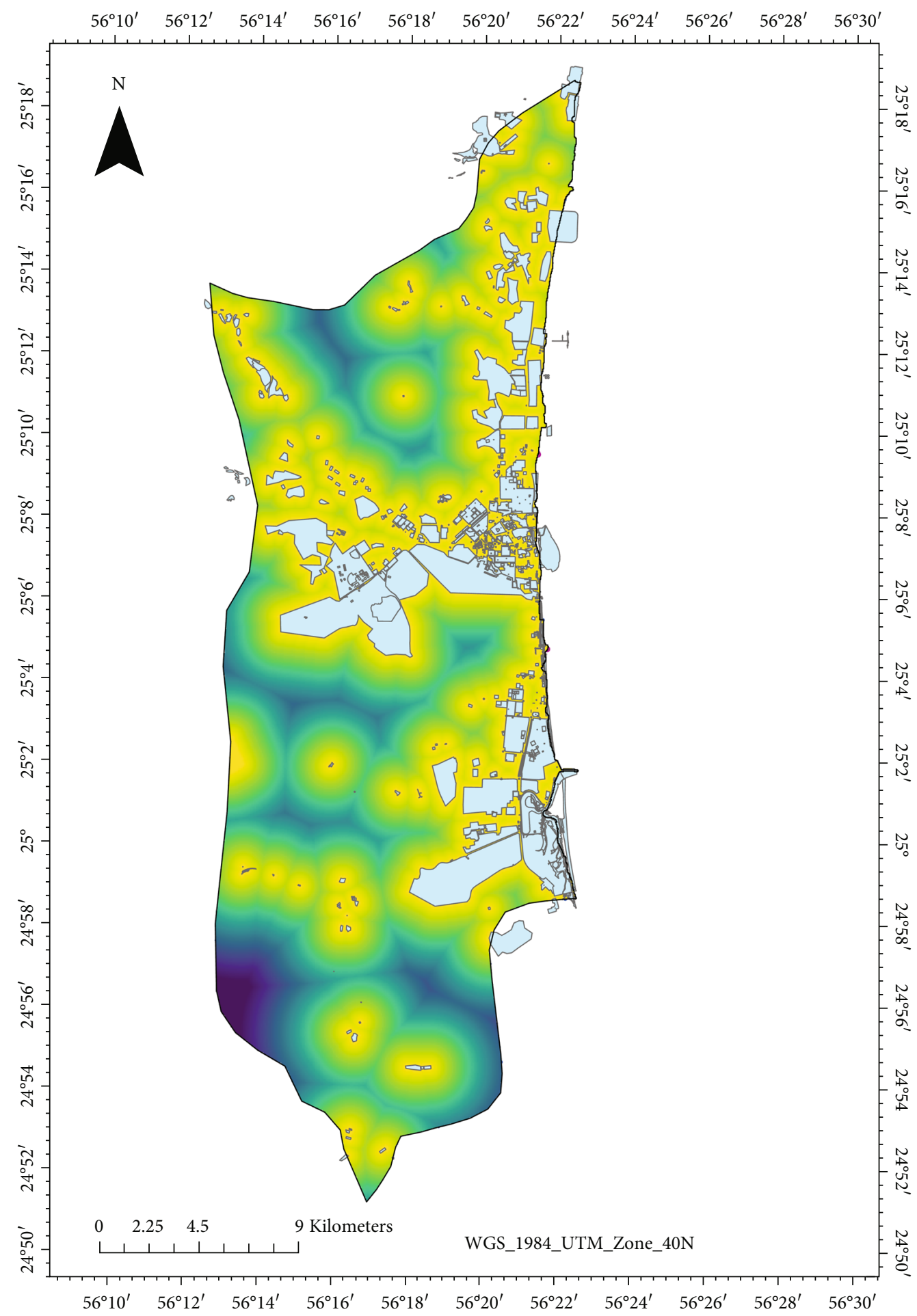

Distance from residences $(\mathrm{m})$

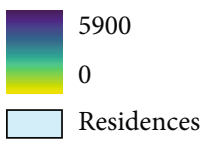

(e)

Figure 5: Continued. 


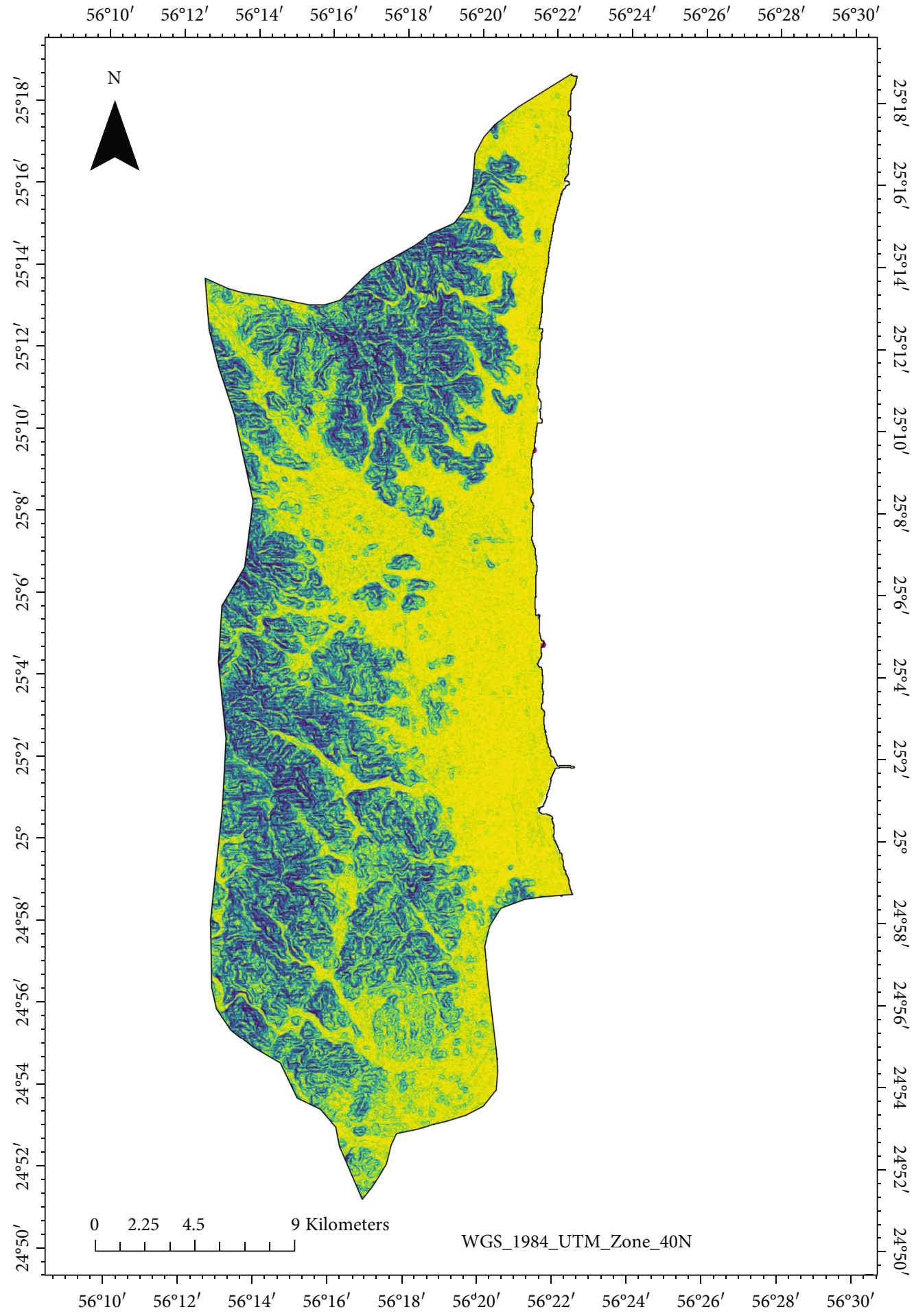

Slope (degrees)

62
0

(f)

Figure 5: Continued. 


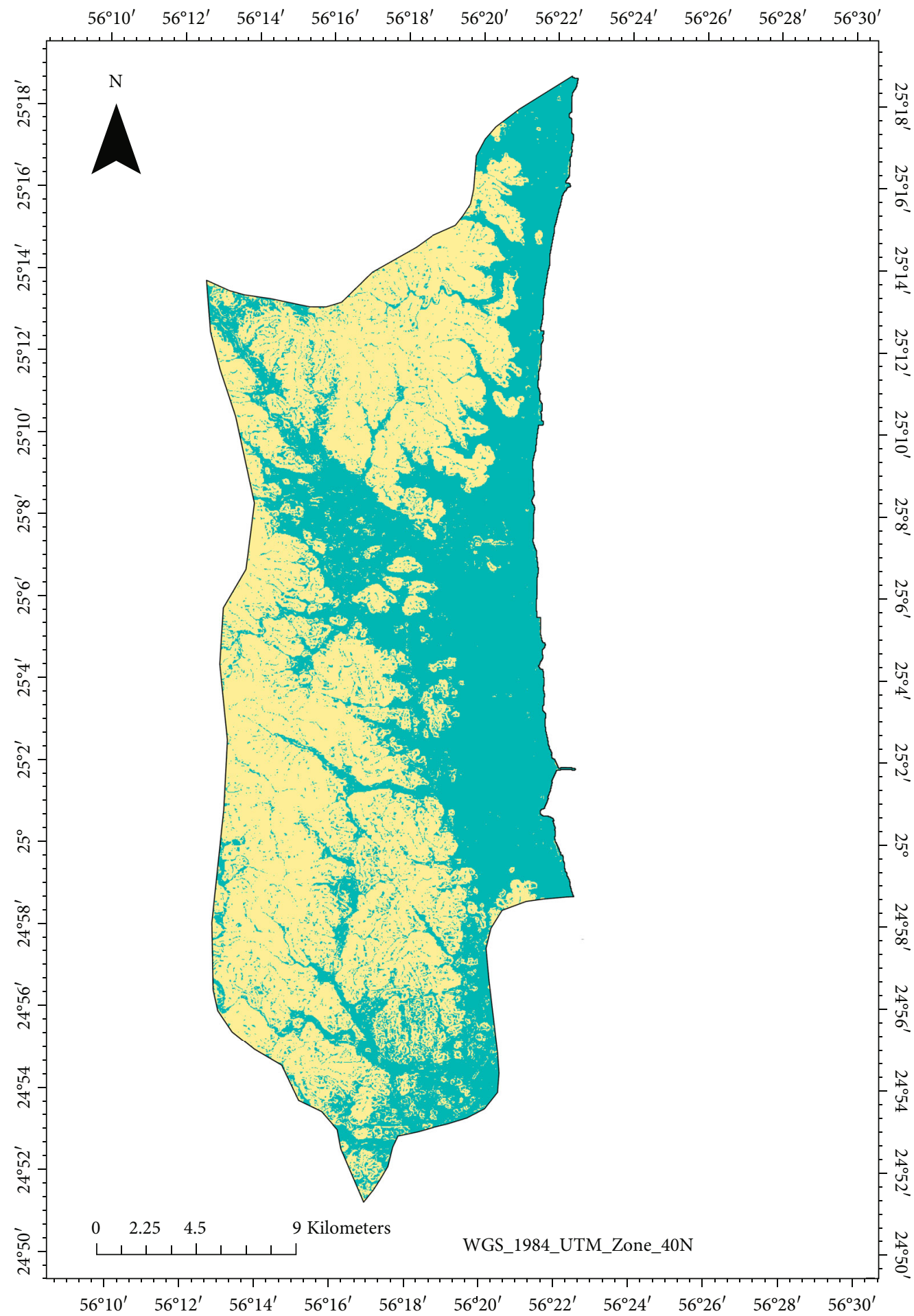

Conifined area

Confined

Not-confined

(g)

Figure 5: Continued. 


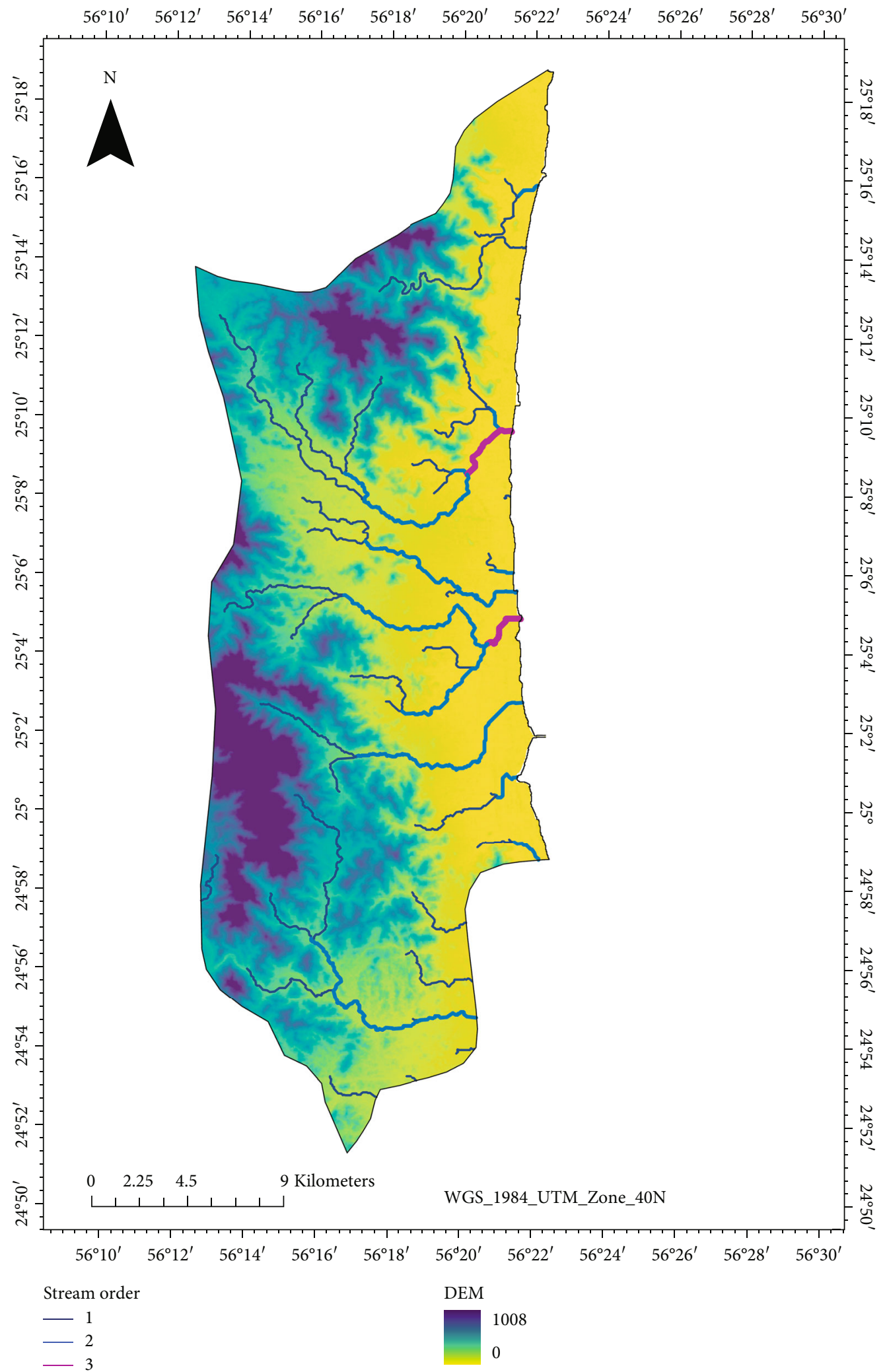

(h)

Figure 5: Thematic layers for vulnerability assessment parameters. (a) Distance from shoreline. (b) Distance from schools. (c) Distance from roads. (d) Distance from hospitals. (e) Distance from residences. (f) Slope. (g) Confined area. (h) Stream order. 
vulnerable areas are those with distances from shore less than $3 \mathrm{~km}$. A buffer of $0.5 \mathrm{~km}$ was restricted while reclassifying

(ii) Schools. The vulnerability assessment was inversely proportional to a school's distance because open spaces, such as school playgrounds, are considered evacuation areas during a disaster [9]. The Euclidean distance thematic layer was prepared using a school's locations from OSM, as shown in Figure 5(b). The farther the assigned distance from schools, the higher the ranking. In this study, the degree of vulnerability increases as the distance from schools increases with the least effect occurring when schools are at an easily accessible distance of less than $2 \mathrm{~km}$ and the most vulnerable when distances are more than $6 \mathrm{~km}$

(iii) Roads. Similar to schools, roads are also considered evacuation areas during hazards [36]. The farther the distance from roads, the higher the risk of vulnerability, refer to Figure 5(c). Road network shapefile database was prepared utilizing OSM, and then Euclidean distance was calculated. Therefore, the highest rank was assigned to roads that are located at a distance of more than $3.5 \mathrm{~km}$. In this study, the degree of vulnerability increases as the distance from roads increases with the least effect occurring when roads are at a distance less than $1.5 \mathrm{~km}$ and the most vulnerable when distances are more than $3.5 \mathrm{~km}$

(iv) Hospitals. Open spaces at a hospital's boundaries are considered evacuation areas during hazards and provided to medical facilities [36]. Euclidean distances were calculated using a hospital's point shapefile which was obtained from OSM, refer to Figure 5(d). The farther the distances from hospitals, the higher ranks were assigned in accordance with Saaty's AHP approach, signifying higher vulnerability. In this study, the degree of vulnerability increases as the distance from hospitals increases with the least effect occurring when hospitals are at a distance less than $2 \mathrm{~km}$ and the most vulnerable when distances are more than $9 \mathrm{~km}$

(v) Distance from Residences. Residential areas were considered highly vulnerable and were assigned the highest rank [2]. This thematic layer was prepared using the polygon shapefile of residential areas utilizing dataset from OSM, refer to Figure 5(e). Areas without residences were assigned the lowest rank

(2) Topographic Factors. The topographic factors considered in the current study were slope and confined area. The thematic layers for both parameters were created using a DEM of the Fujairah Emirate scaled at $30 \mathrm{~m}$ spatial resolution.

(i) Slope. The slope thematic layer is presented in Figure 5(f). The risk of vulnerability increases as slope increases. The slope map was derived utilizing DEM from USGS website. Five classes were considered when reclassifying the slope layer by using the natural breaks (Jenks) technique. Over the years, built-up areas have expanded along the foothills of the Fujairah Emirate. Steeper slopes are more prone to landslides [2, 27, 46], contributing to additional hazards after a disaster to built-up areas constructed close to foothills. The degree of vulnerability increases as the angle of slope increases, with the least effect occurring at angles less than 10 degrees and the most vulnerable areas are those with slope angles more than 30 degrees

(ii) Confined Areas. In the current research, confined areas are considered spaces between mountains and the sea. The confined areas were demarcated by utilizing Landsat 8 images, and subsequently, raster files have been obtained. As observed from the DEM thematic layer, i.e., Figure 5(g), the mountains' foothills begin at an elevation of approximately $450 \mathrm{~m}$ above sea level, and their peak can be observed up to $1008 \mathrm{~m}$. The space covering elevation below $450 \mathrm{~m}$ and within the proximity to the shoreline and streams was considered confined space. Confined spaces are more vulnerable to earthquakes as compared to nonconfined spaces

(3) Hydrology Factors. Stream orders were obtained for Fujairah City by using the hydrology tool in ArcGIS, as shown in Figure 5(h). Stream order is one of the important parameters for assessing vulnerability and creating a risk map.

(i) Distance from Streams. Areas near streams are more susceptible to risk because a water body will interfere with adjacent built-up areas, causing additional harm to livelihood, refer to Figure 5(h). Streams increase the vibration and lubrication of soil. Hence, built-up areas close to streams exhibit higher chances of collapsing, aggravating the risk $[4,46]$. Strahler method [50] was implied to extract the stream order represented in Figure 5(h). Third-order streams are constituted in the eastern part of the study area. Euclidean distance tool was applied to extract the distance from streams thematic layer. Areas near streams were assigned higher ranks in the AHP ranking system. The degree of vulnerability decreases as the distance from streams increases with the least effect occurring at distances of more than $3.5 \mathrm{~km}$, and the most vulnerable areas are those with distances from streams less than $0.5 \mathrm{~km}$

3.2.3. Pairwise Analysis of Parameters. Similar to the seismic spatial analysis discussed in the previous sections, vulnerability assessment was also performed using the AHP approach. Literature review and expert opinions were the basis for weights of each parameter, refer to Table 5 . Weights were assigned in a square matrix that represents diagonal 
TABLE 5: Weights and ranks of the reviewed factors for vulnerability assessment.

\begin{tabular}{|c|c|c|c|c|}
\hline Vulnerability assessment based on & Thematic layers & Class value & Rank & Weights \\
\hline \multirow{19}{*}{ Spatial Euclidean distances } & \multirow{4}{*}{ Distance from shoreline } & $1-3 \mathrm{~km}$ & 9 & \multirow{5}{*}{$5 \%$} \\
\hline & & $3-5 \mathrm{~km}$ & 5 & \\
\hline & & $5-8 \mathrm{~km}$ & 3 & \\
\hline & & $\geq 9 \mathrm{~km}$ & 1 & \\
\hline & \multirow{4}{*}{ Distance from the schools (for evacuation) } & $1-2 \mathrm{~km}$ & 1 & \\
\hline & & $2-4 \mathrm{~km}$ & 3 & \multirow{3}{*}{$7 \%$} \\
\hline & & $4-6 \mathrm{~km}$ & 5 & \\
\hline & & $6-8 \mathrm{~km}$ & 7 & \\
\hline & \multirow{4}{*}{ Distance from roads } & $0.5-1.5 \mathrm{~km}$ & 1 & $25 \%$ \\
\hline & & $1.5-2.5 \mathrm{~km}$ & 3 & \multirow{7}{*}{$7 \%$} \\
\hline & & $2.5-3.5 \mathrm{~km}$ & 5 & \\
\hline & & $\geq 3.5 \mathrm{~km}$ & 9 & \\
\hline & \multirow{5}{*}{ Distance from hospitals } & $1-2 \mathrm{~km}$ & 1 & \\
\hline & & $2-4 \mathrm{~km}$ & 3 & \\
\hline & & $4-6 \mathrm{~km}$ & 5 & \\
\hline & & $6-8 \mathrm{~km}$ & 7 & \\
\hline & & $\geq 9 \mathrm{~km}$ & 9 & \multirow{3}{*}{$20 \%$} \\
\hline & \multirow{2}{*}{ Distance from residences } & Houses & 9 & \\
\hline & & No houses & 1 & \\
\hline \multirow{6}{*}{ Topographic factors } & \multirow{4}{*}{ Slope (degrees) } & $30<$ & 9 & \multirow{4}{*}{$6 \%$} \\
\hline & & $15-30$ & 7 & \\
\hline & & $10-15$ & 5 & \\
\hline & & $0-10$ & 3 & \\
\hline & \multirow{2}{*}{ Confined area } & Confined & 9 & \multirow{2}{*}{$20 \%$} \\
\hline & & Not confined & 1 & \\
\hline \multirow{4}{*}{ Hydrology } & \multirow{4}{*}{ Distance from streams } & $0.5-1.5 \mathrm{~km}$ & 9 & \multirow{4}{*}{$10 \%$} \\
\hline & & $1.5-2.5 \mathrm{~km}$ & 5 & \\
\hline & & $2.5-3.5 \mathrm{~km}$ & 3 & \\
\hline & & $>3.5 \mathrm{~km}$ & 1 & \\
\hline
\end{tabular}

TABLE 6: Pairwise comparison matrix for vulnerability assessment parameters.

\begin{tabular}{lcccccccc}
\hline & E.D. roads & E.D. shoreline & Confined & E.D. residential & E.D. schools & Slope & E.D. hospitals & E.D. streams \\
\hline E.D. roads & 1.000 & 5.000 & 1.250 & 1.250 & 3.571 & 4.167 & 3.571 & 2.500 \\
E.D. shoreline & 0.200 & 1.000 & 0.250 & 0.250 & 0.714 & 0.833 & 0.714 & 0.500 \\
Confined area & 0.800 & 4.000 & 1.000 & 0.900 & 2.857 & 3.333 & 2.857 & 2.000 \\
E.D. residential & 0.800 & 4.000 & 1.111 & 1.000 & 2.857 & 3.333 & 2.857 & 2.000 \\
E.D. schools & 0.280 & 1.400 & 0.350 & 0.350 & 1.000 & 1.167 & 0.900 & 0.700 \\
Slope & 0.240 & 1.200 & 0.300 & 0.300 & 0.857 & 1.000 & 0.857 & 0.600 \\
E.D. hospitals & 0.280 & 1.400 & 0.350 & 0.350 & 1.111 & 1.167 & 1.000 & 0.700 \\
E.D. streams & 0.400 & 2.000 & 0.500 & 0.500 & 1.429 & 1.667 & 1.429 \\
\hline
\end{tabular}

${ }^{*}$ E.D.: Euclidean distance.

elements as 1 on the basis of several vulnerability assessment studies $[4,17,27]$.

Each parameter's weights helped develop a pairwise comparison (Table 6) to understand and validate relative weights among each parameter. The matrix helped to calculate $\mathrm{CI}$, RI, and $\mathrm{CR}$, by utilizing the equations mentioned in Section 3.1.2 to validate the proposed risk assessment model. The resulting $\mathrm{CR}$ was also $3 \%$, validating the model as a good one for the ranking and weighting system. 


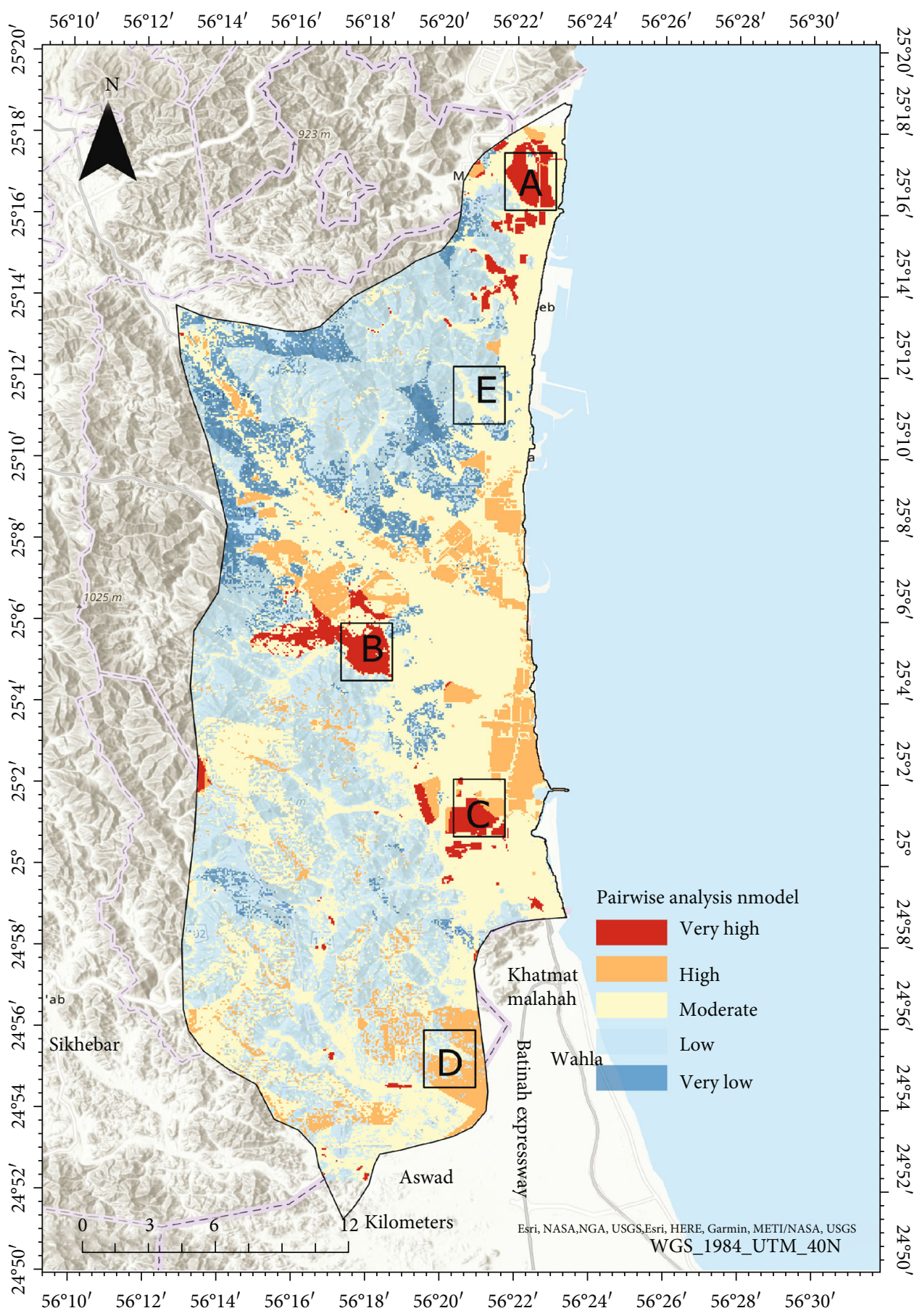

(a)

Figure 6: Continued. 


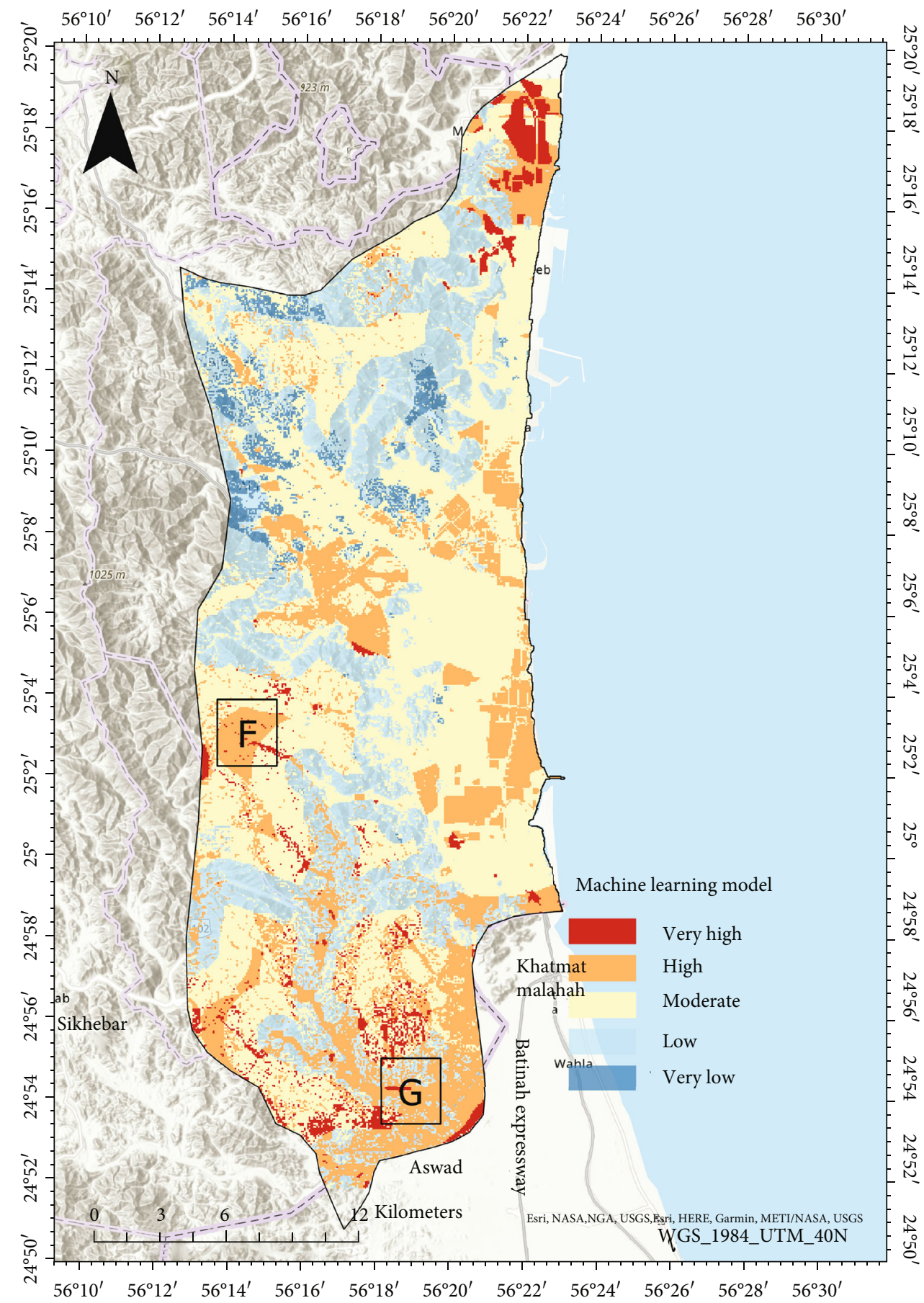

(b)

Figure 6: Risk map. (a) Pairwise analysis model. (b) ML model (SVM).

3.2.4. Machine Learning (ML) Analysis of Parameters. ML techniques are boon for modern-day research in all the scientific domains $[28,33,51-56]$. It allows the input data to read, analyse, and train up to maximum accuracy compared to any traditional approaches. Several studies $[19,32,51,57]$ of earthquake risk assessment have utilized ML techniques paired with traditional approaches. This study utilizes three ML models: SVM, DT, and RF to classify most risk-prone zones within Fujairah and its surrounding towns. The research established 500 random points across the study area to train the ML algorithms. Each thematic layer developed for this study was the independent parameter, and the potential risk was the dependent parameter for the ML models. The raw data was first preprocessed to remove any null values or outliers. This is essential so that the ML model is able to train and learn properly. The next important step is to split the data in order to remove the bias from the training process of the ML algorithm. Often, the ML algorithms fit 
TABLE 7: Comparison of risk classification areas (as a percentage of total area).

\begin{tabular}{lcc}
\hline Risk classification & AHP & ML \\
\hline Very high & $3.6 \%$ & $0.3 \%$ \\
High & $9.5 \%$ & $10.8 \%$ \\
Moderate & $41.1 \%$ & $25.9 \%$ \\
Low & $38.0 \%$ & $49.0 \%$ \\
Very low & $7.9 \%$ & $14.1 \%$ \\
\hline
\end{tabular}

TABLE 8: Accuracy and standard deviation of ML techniques.

\begin{tabular}{lcc}
\hline Machine learning models & Accuracy & Standard deviation \\
\hline Support vector machine & $79.6 \%$ & $\pm 6.5 \%$ \\
Decision tree & $78.9 \%$ & $\pm 4.1 \%$ \\
Random forest & $78.2 \%$ & $\pm 4.4 \%$ \\
\hline
\end{tabular}

TABle 9: Confusion matrix of SVM technique.

\begin{tabular}{lcccc}
\hline & $\begin{array}{c}\text { True } \\
\text { "low" }\end{array}$ & $\begin{array}{c}\text { True } \\
\text { "moderate" }\end{array}$ & $\begin{array}{c}\text { True } \\
\text { "high" }\end{array}$ & $\begin{array}{c}\text { Class } \\
\text { precision }\end{array}$ \\
\hline $\begin{array}{l}\text { Predicted "low" } \\
\begin{array}{l}\text { Predicted } \\
\text { "moderate" }\end{array}\end{array}$ & 52 & 11 & 3 & $78.79 \%$ \\
$\begin{array}{l}\text { Predicted "high" } \\
\text { Class prediction }\end{array}$ & 10 & 47 & 3 & $78.33 \%$ \\
\hline
\end{tabular}

too tightly on the training data, leading to incorrect predictions on the test data.

(1) Support Vector Machine (SVM). SVM is the first ML algorithm utilized to analyse the earthquake datasets. SVM is one of the most regularly utilized supervised learning algorithms for classification and regression analysis and provides practical learning tasks. The SVM takes the input data and predicts the class for each data. For this study, $60 \%$ of the dataset was used for training, and $40 \%$ was utilized as a test dataset. The classification is performed by identifying hyperplane boundaries between the classes such that the boundary lines are as far as possible from the classes. By using the dot kernel type, the weights for the attributes are also obtained $[33,51,58,59]$. The hyperplane is constructed using the following function:

$$
f(x)=<\mathrm{w} \cdot \mathrm{x}>+\mathrm{b}=\sum_{i=1}^{n} w_{i} x_{i}+b,
$$

where $i$ is the attributes at each instance and $w$ is the weights. The SVM model in this study performed $79.6 \%$ accuracy.

(2) Decision Tree (DT). A decision tree is a supervised learning algorithm that identifies the essential parameters that can help in classification. The rules are worked out based on the structure of the data. The tree starts with a highly influential attribute as the root node and successive rules are applied to move to the next attributes until a leaf node or terminal node is reached [60,61]. The data set is split repeatedly from the coarsest attributes to the finest attributes. DT have the advantage of generating a visually easy to interpret model. The DT model in this study gave an accuracy of $78.9 \%$. The optimal depth of the tree was obtained to be 4 with an error rate of $16 \%$.

(3) Random Forest (RF). RF is one of the most used supervised learning algorithms in ML. A RF is a group of random decision trees where each node splits the dataset based on a particular parameter. Only a few attributes are considered for the selection at each node. This selection is specified as a parameter while designing the model. Based on the splitting rules at each node, the dataset is classified among the possible outcomes. New nodes are continuously built till a criterion is satisfied at which point the tree terminates. Each tree results in a single outcome, and the final outcome of the $\mathrm{RF}$ is the average of all the individual trees [62]. While splitting at a node, RF uses the best attribute among all the attributes rather than selecting the most important attribute. RF gave an accuracy of $78.2 \%$ in this study. The optimal parameters were obtained at a tree depth of 4 and the number of trees as 20 with an error rate of $16.3 \%$.

\section{Results and Discussion}

The earthquake risk was estimated and mapped by two approaches, AHP and ML, spatially (refer to Figures 6(a) and $6(\mathrm{~b})$ ). The map was categorised on the basis of ordinal scale into 5 classes: "very high," "high," "moderate," "low," and "very low." Though both the maps depicted a similar pattern for adversity, marginal differences in each class area were estimated, refer to Table 7. As can be seen from Table 7, the area under "very high" category in AHP was 12 times more than in ML. Similarly, in "very low" category, ML has almost twice the area than AHP. The "very high" risk zones in the AHP output map were categorised as "high" risk zones in the ML output map. Additionally, two more zones were identified as "high" risk zones in the ML output which were not observed in the AHP output. Three central locations were identified as belonging to the "very high" risk category according to the AHP output Figure 6(a).

The risk map was obtained by multiplying hazard and vulnerability. Three ML models-SVM, DT, and RF-were applied to the dataset using Rapidminer software. $60 \%$ of the dataset was categorised as training and $40 \%$ as testing for ML models. SVM presented the highest accuracy of 79.6\% (Table 8) compared to the DT (78.6\%) and RF (78.2\%). The SVM model draws a standard deviation of $\pm 6.5 \%$. Table 9 represents the confusion matrix accuracy of the same model. The True "high" accuracy is almost $87 \%$ representing the training and testing datasets. SVM facilitated the assignment of weights to each parameter in a more accurate way. The total area for "very high" and "high" risk was estimated to be $20 \mathrm{~km}^{2}$ and $114 \mathrm{~km}^{2}$, respectively, for the 


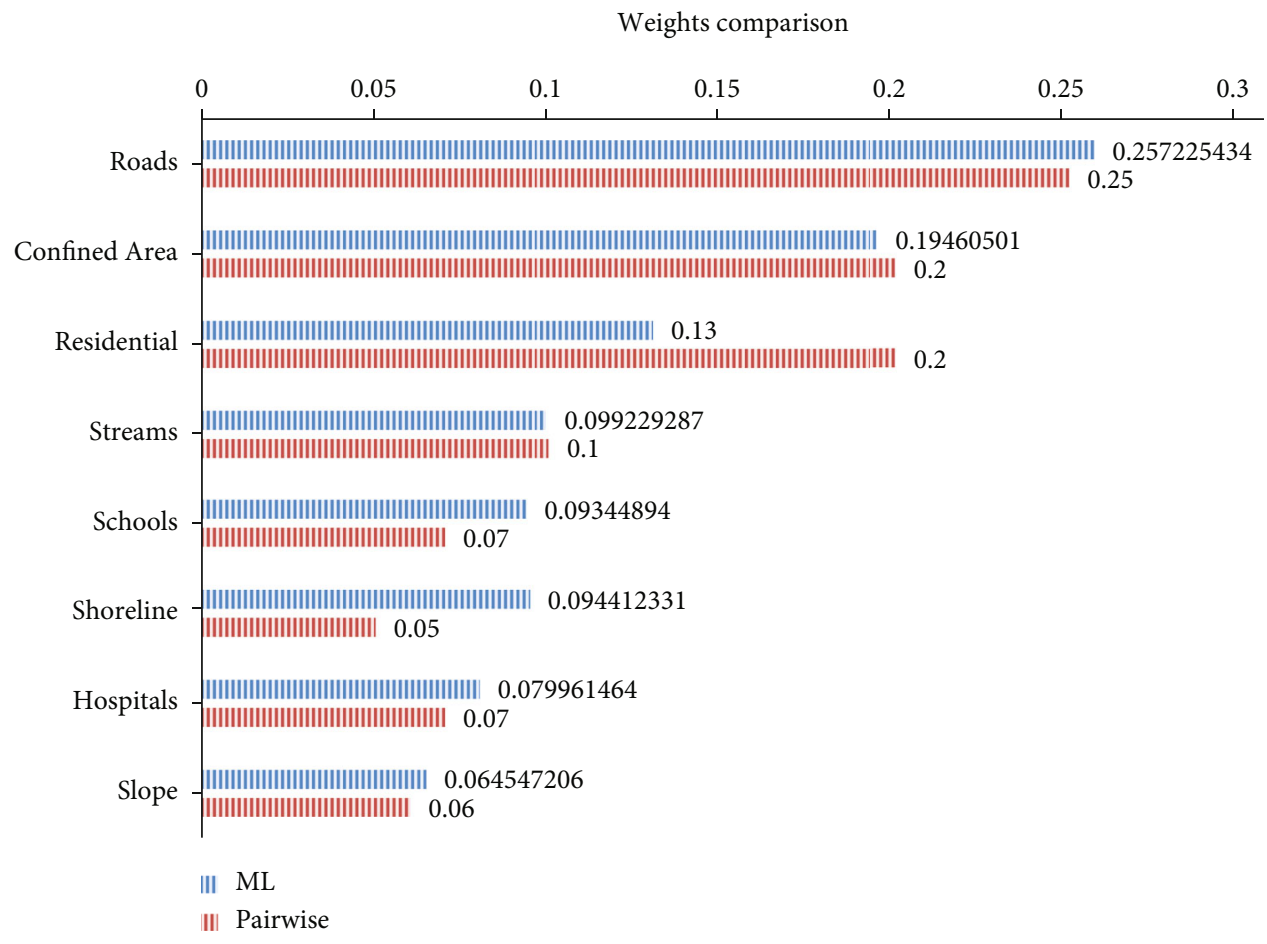

FIGURE 7: Weights comparison of pairwise and ML technique.

ML output. These zones are identified to be very close to streams and shoreline and are classified as confined areas.

Figure 7 represents the comparison of the weight of each input parameter derived from AHP and ML techniques. A key difference in weights can be observed from both techniques. In the AHP model, utmost importance to roads, confined areas, and residential areas have been allotted. The ML approach validated the AHP technique by concluding the highest weights to similar parameters. However, minute upswing in weights for the residential area can be seen for AHP. ML approach moderately assigned more weightage to evacuation centres like schools and hospitals. Also, the weights for distance from shoreline were increased to two times in the ML technique.

The following points were concluded from both maps (Figure 6):

(i) Zone A portrays one of the very high-risk zones from both approaches. It is situated in Fujairah's north-eastern part, within $1 \mathrm{~km}$ from the shoreline, and is a compact industrial area with large oil storage tankers, as shown in Figure 2(a). The area is bounded by mountains of height 180 ?m (above sea level) in the west, as shown in Figure 2(b), and the Gulf of Oman in the east, as shown in Figure 2(c). Being an industrial region, it is far from evacuation areas, such as the open spaces of schools and hospitals which are located at $4 ? \mathrm{~km}$ and $7 ? \mathrm{~km}$, respectively, thereby, posing a hurdle for evacuation during times of disaster.

(ii) Zone B shows identical patterns in both the outputs. AHP has a higher proportion of area under "very high" than ML has under "high" risk. Like Zone A, this zone is also a confined area with mountains of $150 \mathrm{~m}$ height in the west and has a compact builtup of residences, as shown in Figures 2(b) and 2(d). It is considerably closer to streams at a distance of $2 \mathrm{~km}$ and $6 \mathrm{~km}$ far from schools.

(iii) Zone $\mathrm{C}$ is a combination of confined and residential areas, making it a very high-risk zone (refer to Figure 6(a)). This zone is close to the Gulf of Oman and approximately $3 \mathrm{~km}$ from the shoreline, in the Kalba region. This region categorised as "very high" in AHP was observed to be in the "high" category in ML.

(iv) Zone $\mathrm{D}$ is another high-risk zone, with similar contributing major parameters as Zones A, B, and C, i.e., closeness to residential and confined areas. Other parameters that play a role are its close proximity to streams (within $4 \mathrm{~km}$ ) and distance from schools $(2 \mathrm{~km})$.

(v) Zone E is categorised as a low-risk zone. Although the region is closer to the shoreline at a distance of $5 \mathrm{~km}$, the contributing parameters were roads and schools located at a distance less than $2 \mathrm{~km}$. Moreover, this zone is located approximately $4 \mathrm{~km}$ away from streams. These factors contribute to the "low" risk categorization of this zone, validating the AHP ranking and weighting approach.

(vi) Zone $\mathrm{F}$ lies within $1.5 \mathrm{~km}$ range from streams and has a moderately higher slope of 35-40 degrees. The region is farther from evacuation centres such 
as hospitals and roads making it a "moderate" risk zone, Figure 6(a), whereas it is classified as a "high" risk zone in Figure 6(b)

(vii) Zone $\mathrm{G}$ is closer to Zone $\mathrm{E}$. As the weights are slightly higher for the distance from schools in the ML technique, the output showed more percentage of areas to be "high" risk as compared to the AHP technique. Also, this zone has been identified to be close to streams at a distance less than $1.5 \mathrm{~km}$, unlike Zone E.

The above discussion also leads the scientific society to investigate and study the consequences of coseismic secondary effects $[63,64]$. With respect to the present research, the secondary effects might arise from tsunamis, landslides, liquefaction of soil, faults, and cracks through mountains, oil spillage from industry belts, collapse of high rise residential buildings, and fire hazards due to natural gas or oil spillage [63]. These effects might result in the compounding of the earthquake hazard and might lead to more widespread calamities and human life destruction. In the event of future occurrence of an earthquake, the area has a higher possibility of being affected by tsunami as a coseismic effect despite no fatalities in the study area until now [37].

\section{Conclusion}

This study represents an effort to assess UAE's vulnerability to seismic activities. Although the UAE has not been directly affected by any major earthquakes to date, the eastern part of the country has experienced high-magnitude (3-5 M) tremors [3, 9, 12, 13, 37, 49], and thus, an earthquake vulnerability assessment is necessary. Spatial statistical techniques obtained from a previous study [32, 57] were utilized to determine the earthquake event pattern over the Arabian Plate and locate hazard-prone areas in the UAE. These techniques helped determine that most high-hazard events are observed in the northern belt of the Arabian Plate covering the Zagros Mountains of Iran. PGA, distance from faults, slope percent, soil classification, and geology were the parameters integrated in Saaty's AHP to determine seismicprone zones in UAE. One of the major outcomes from the seismic hazard map was that the eastern part of the UAE is more likely seismically prone, particularly Fujairah City and adjacent towns, such as Kalba, Al Aqdah, Hail, Al Bithnah, and Qurayya. Subsequently, the study evaluated the hazard risk and charted integrated AHP and ML techniques to obtain the risk map. Three ML techniques (i.e. SVM, DT, and RF) were attempted, and accuracy of each was intercompared. T Another major accomplishment in the study is that the SVM model showed the highest accuracy of $79.6 \%$ with $60 \%$ of the dataset as a training dataset and $40 \%$ as testing dataset. The SVM-generated weights were utilized to validate and revise the AHP weights for vulnerability parameters. Finally, the weighted overlay technique facilitated to development of the risk map and categorised the risk zones into very high, high, moderate, low, and very low. Risk map obtained from both approaches AHP and ML was compared. The parameters utilized for the risk assessment were the distance from the shoreline, schools, hospitals, roads, residences, streams, and confined areas. Confined areas and compact built-up regions with residences or industries located closer to the shoreline or streams were the most vulnerable. Schools, hospitals, and roads were considered evacuation areas during hazards. A shorter distance from vulnerable areas to these evacuation areas is more favourable because of their open spaces. The farther the distances of the evacuation areas, the higher the risk. The region with low vulnerability was identified to be located at a distance of approximately $2 \mathrm{~km}$ and $5 \mathrm{~km}$ from schools and the shoreline/streams, respectively. Approximately, $20 \mathrm{~km}^{2}$ and $114 \mathrm{~km}^{2}$ were estimated to lie under "very high" and "high" risk zones, respectively, in ML. The ML approach demonstrated results in a more refined way and also aided in validation of the conventional AHP approach. The methodology developed in this research will assess seismic-prone areas and the risk associated with earthquake hazard. This approach can be utilized to deal with disasters and is beneficial for the disaster management of a country, such as the UAE. It can also be applied to other geographies.

\section{Data Availability}

The data used to support the findings of this study are available from the first author upon request and upon approval of the data source.

\section{Conflicts of Interest}

The authors declare that there is no conflict of interest regarding the publication of this paper.

\section{Authors' Contributions}

D.A.-D. and R.A.-R. developed the concept and the methodology of the study. D.A.-D., R.A.-R., K.S., and S.M. conducted the spatial processing to develop the required thematic layers and also carried out the AHP weighting approach for vulnerability analysis. D.A.-D., R.A.-R., K.S., S.A.-M., and S.M. conducted spatial processing and carried out the AHP weighting approach for vulnerability analysis. D.A.-D., R.A.-R., K.S., B.K., and S.A.-A. contributed in selecting the most seismically active region. D.A.-D., R.A.-R., K.S., S.A.-M, S. M, B.K., S.A.-A., and H.A.-A contributed in selecting the most vulnerable region after hazard. R.A.-R., B.K., H.A.-A., and N.U edited, restructured, and professionally optimized the manuscript. D.A.-D., R.A.-R., B.K., K.S., S.A.M, S.M.,H.A.-A., and N.U. prepared and reviewed the manuscript.

\section{References}

[1] K. Al-Ahmadi, A. Al-Amri, and L. See, "A spatial statistical analysis of the occurrence of earthquakes along the Red Sea floor spreading: clusters of seismicity," Arabian Journal of Geosciences, vol. 7, no. 7, pp. 2893-2904, 2014. 
[2] A. M. Duncan and D. K. Chester, "United Arab Emirates: disaster management with regard to rapid onset natural disasters," in Advanced ICTs for disaster management and threat detection: collaborative and distributed frameworks, pp. 6579, IGI Global, 2010.

[3] S. A. Barakat, A. Shanableh, and A. I. H. Malkawi, "A comparative earthquakes risk assessment approach applied to the United Arab Emirates," Jordan Journal of Civil Engineering, vol. 2, no. 2, pp. 139-151, 2008.

[4] P. Yariyan, M. Avand, F. Soltani, and O. Ghorbanzadeh, "Earthquake vulnerability mapping using different hybrid models," Symmetry, vol. 12, no. 3, p. 405, 2020.

[5] G. Aldama-Bustos, J. J. Bommer, C. H. Fenton, and P. J. Stafford, "Probabilistic seismic hazard analysis for rock sites in the cities of Abu Dhabi, Dubai and Ra's Al Khaymah, United Arab Emirates," Georisk: Assessment and Management of Risk for Engineered Systems and Geohazards, vol. 3, no. 1, pp. 1-29, 2009.

[6] V. Pascucci, M. W. Free, and Z. A. Lubkowski, "Seismic hazard and seismic design requirements for the Arabian Peninsula region," in 14th World Conference in Earthquake Engineering, Beijing, 2008Paper 07-0151.

[7] R. Al-Ruzouq, K. Hamad, A. Shanableh, and M. Khalil, "Infrastructure growth assessment of urban areas based on multitemporal satellite images and linear features," Annals of GIS, vol. 23, no. 3, pp. 183-201, 2017.

[8] National Response Framework, United Arab Emirates, National Emergency Crisis and Disasters Management Authority, First edition, 2013, https://www.ncema.gov.ae.

[9] A. M. Mwafy, "Classification and idealization of the building stock in the UAE for earthquake loss estimation," in 15th World Conference on Earthquake Engineering, Lisbon, Portugal, 2012.

[10] A. Issa and A. Mwafy, "Fragility assessment of pre-seismic code buildings and emergency facilities in the UAE," in Second European conference on earthquake engineering and seismology (2ECEES), pp. 2-4, Istanbul, Turkey, 2014.

[11] M. AlHamaydeh, S. Abdullah, A. Hamid, and A. Mustapha, "Seismic design factors for RC special moment resisting frames in Dubai, UAE," Earthquake Engineering and Engineering Vibration, vol. 10, no. 4, pp. 495-506, 2011.

[12] B. Kalantar, N. Ueda, H. A. H. Al-Najjar, and A. A. Halin, "Assessment of convolutional neural network architectures for earthquake-induced building damage detection based on pre-and post-event orthophoto images," Remote Sensing, vol. 12, no. 21, p. 3529, 2020.

[13] R. Sawires, J. A. Peláez, M. AlHamaydeh, and J. Henares, “A state-of-the-art seismic source model for the United Arab Emirates," Journal of Asian Earth Sciences, vol. 186, p. 104063, 2019.

[14] R. Sawires, J. A. Peláez, and M. Hamdache, "Probabilistic seismic hazard assessment for United Arab Emirates, Qatar and Bahrain," Applied Sciences, vol. 10, no. 21, p. 7901, 2020.

[15] A. Ansal, A. Akinci, G. Cultrera et al., "Loss estimation in Istanbul based on deterministic earthquake scenarios of the Marmara Sea region (Turkey)," Soil Dynamics and Earthquake Engineering, vol. 29, no. 4, pp. 699-709, 2009.

[16] J. G. Liu, P. J. Mason, E. Yu et al., "GIS modelling of earthquake damage zones using satellite remote sensing and DEM data," Geomorphology, vol. 139-140, pp. 518-535, 2012.

[17] H. Bahadori, A. Hasheminezhad, and A. Karimi, "Development of an integrated model for seismic vulnerability assess- ment of residential buildings: application to Mahabad City, Iran," Journal of Building Engineering, vol. 12, pp. 118-131, 2017.

[18] B. Byron, W. Nadine, S. David, S. John, and B. B. Walker, "GIS - based multicriteria evaluation for earthquake response : a case study of expert opinion in Vancouver, Canada," Natural Hazards, vol. 105, no. 2, pp. 2075-2091, 2021.

[19] P. Yariyan, H. Zabihi, I. D. Wolf, M. Karami, and S. Amiriyan, "Earthquake risk assessment using an integrated Fuzzy Analytic Hierarchy Process with Artificial Neural Networks based on GIS: a case study of Sanandaj in Iran," International Journal of Disaster Risk Reduction, vol. 50, article 101705, 2020.

[20] S. F. Cinicioglu, I. Bozbey, S. Oztoprak, and M. K. Kelesoglu, "An integrated earthquake damage assessment methodology and its application for two districts in Istanbul, Turkey," Engineering Geology, vol. 94, no. 3-4, pp. 145-165, 2007.

[21] I. Pal, S. K. Nath, and K. Shukla, "Earthquake hazard zonation of Sikkim Himalaya using a GIS platform," Natural Hazards, vol. 45, no. 3, pp. 333-377, 2008.

[22] T. Erden and H. Karaman, "Analysis of earthquake parameters to generate hazard maps by integrating AHP and GIS for Küçükçekmece region," Natural Hazards and Earth System Sciences, vol. 12, no. 2, pp. 475-483, 2012.

[23] W. K. Mohanty, M. Y. Walling, S. K. Nath, and I. Pal, "First order seismic microzonation of Delhi, India using geographic information system (GIS)," Natural Hazards, vol. 40, no. 2, pp. 245-260, 2007.

[24] H. D. Skilodimou, G. D. Bathrellos, K. Chousianitis, A. M. Youssef, and B. Pradhan, "Multi-hazard assessment modeling via multi-criteria analysis and GIS: a case study," Environment and Earth Science, vol. 78, no. 2, 2019.

[25] M. Moradi, M. R. Delavar, and B. Moshiri, "A GIS-based multi-criteria analysis model for earthquake vulnerability assessment using Choquet integral and game theory," Natural Hazards, vol. 87, no. 3, pp. 1377-1398, 2017.

[26] D. Toma-Danila, C. O. Cioflan, and I. Armas, "GIS in seismology: contributions to the evaluation of seismic hazard and risk," GeoPatterns, vol. 2, no. 2, pp. 10-16, 2017.

[27] S. S. Esmael, Seismic risk assessment using geographical information system (GIS) with analytic hierarchy process (AHP):, [Ph.D. thesis], Anadolu University (Turkey), Eskişehir, Turkey, 2018.

[28] R. Jena, B. Pradhan, S. P. Naik, and A. M. Alamri, "Earthquake risk assessment in NE India using deep learning and geospatial analysis," Geoscience Frontiers, vol. 12, no. 3, article 101110, 2021.

[29] S. S. Lin, S. L. Shen, A. Zhou, and Y. S. Xu, "Risk assessment and management of excavation system based on fuzzy set theory and machine learning methods," Automation in Construction, vol. 122, p. 103490, 2021.

[30] H. M. Lyu, W. J. Sun, S. L. Shen, and A. Arulrajah, "Flood risk assessment in metro systems of mega-cities using a GIS-based modeling approach," Science of The Total Environment, vol. 626, pp. 1012-1025, 2018.

[31] S. Lee, M. Panahi, H. R. Pourghasemi et al., "SEVUCAS: a novel GIS-based machine learning software for seismic vulnerability assessment," Applied Sciences, vol. 9, no. 17, p. 3495, 2019.

[32] R. Jena, B. Pradhan, G. Beydoun et al., "Integrated model for earthquake risk assessment using neural network and analytic hierarchy process: Aceh province, Indonesia," Geoscience Frontiers, vol. 11, no. 2, pp. 613-634, 2020. 
[33] Y. Liu, Z. Li, B. Wei, X. Li, and B. Fu, "Seismic vulnerability assessment at urban scale using data mining and GIScience technology: application to Urumqi (China)," Geomatics, Natural Hazards and Risk, vol. 10, no. 1, pp. 958-985, 2019.

[34] P. Hopkins and N. Turan, "Integration of GIS , AHP and TOPSIS for earthquake hazard analysis," Natural Hazards, vol. 92, no. 3, pp. 1523-1546, 2018.

[35] R. A. Ahmad, R. P. Singh, and A. Adris, "Seismic hazard assessment of Syria using seismicity, DEM, slope, active faults and GIS," Remote Sensing Applications: Society and Environment, vol. 6, pp. 59-70, 2017.

[36] M. M. Yagoub, "Spatio-temporal and hazard mapping of earthquake in UAE (1984-2012): remote sensing and GIS application," Geoenvironmental Disasters, vol. 2, no. 1, p. 13, 2015.

[37] R. Sigbjornsson and A. S. Elnashai, "Hazard assessment of Dubai, United Arab Emirates, for close and distant earthquakes," Imperial College Press, vol. 10, no. 5, pp. 749-773, 2006.

[38] D. Aldogom and R. Al-ruzouq, "Geostatistical seismic analysis and hazard assessment; United Arab Emirates," The International Archives of the Photogrammetry, Remote Sensing and Spatial Information Sciences, vol. XLII-3/W4, pp. 29-36, 2018.

[39] A. Deif, Y. Al-Shijbi, I. El-Hussain, M. Ezzelarab, and A. M. E. Mohamed, "Compiling an earthquake catalogue for the Arabian Plate, Western Asia," Journal of Asian Earth Sciences, vol. 147, pp. 345-357, 2017.

[40] D. M. Puteri, A. K. Affandi, S. Sailah, and N. Hudayat, “Analysis of peak ground acceleration (PGA) using the probabilistic seismic hazard analysis (PSHA) method for Bengkulu earthquake of 1900 - 2017 period," Journal of Physics: Conference Series, vol. 1282, p. 012054, 2019.

[41] M. M. Yagoub, A. A. Alsereidi, E. A. Mohamed et al., "Newspapers as a validation proxy for GIS modeling in Fujairah, United Arab Emirates: identifying flood-prone areas," Natural Hazards, vol. 104, no. 1, pp. 111-141, 2020.

[42] N. Takai, G. Shimizu, and S. Okada, "New attenuation formula of earthquake ground motions passing through the volcanic front," $13^{\text {th }}$ World Conference on Earthquake Engineering, vol. 2, no. 731, 2004.

[43] M. Panahi, F. Rezaie, and S. A. Meshkani, "Seismic vulnerability assessment of school buildings in Tehran city based on AHP and GIS," Natural Hazards and Earth System Sciences, vol. 14, no. 4, pp. 969-979, 2014.

[44] M. Bernasconi, C. Choirat, and R. Seri, "The analytic hierarchy process and the theory of measurement," University of Venice "Ca' Foscari", Department of Economics, Working Papers, vol. 56, 2009.

[45] R. Jena, B. Pradhan, and G. Beydoun, "International Journal of Disaster Risk Reduction Earthquake vulnerability assessment in Northern Sumatra province by using a multi-criteria decision-making model," International Journal of Disaster Risk Reduction, vol. 46, article 101518, 2020.

[46] P. De Rosa and A. Fredduzzi, "Stream power determination in GIS : an index to evaluate the most sensitive points of a river," Water, vol. 11, no. 6, p. 1145, 2019.

[47] UNISDR and WMO, Disaster Risk and Resilience Thematic Think Piece, UN Sys. task team on the post-2015 UN development agenda, 2012.

[48] R. Vatseva, D. Solakov, and E. Tcherkezova, "Applying GIS in seismic hazard assessment and data integration for disaster management," in Intelligent Systems for Crisis Management, pp. 171-183, Springer, 2013.

[49] J. A. Abdalla and A. S. Al-Homoud, "SEISMIC hazard assessment of United Arab Emirates and its surroundings," Journal of Earthquake Engineering, vol. 8, no. 6, pp. 817837, 2004.

[50] M. S. Yang and K. T. Lee, "Determination of probability distributions for Strahler stream lengths based on Poisson process and DEM," Hydrological Sciences Journal, vol. 46, no. 5, pp. 813-824, 2001.

[51] S. Zhou and L. Fang, "Support vector machine modeling of earthquake-induced landslides susceptibility in central part of Sichuan province, China," Geoenvironmental Disasters, vol. 2, no. 1, pp. 1-12, 2015.

[52] R. Jena, B. Pradhan, G. Beydoun, A. Al-Amri, and H. Sofyan, "Seismic hazard and risk assessment: a review of state-of-theart traditional and GIS models," Arabian Journal of Geosciences, vol. 13, no. 2, 2020.

[53] H. A. H. Al-Najjar, B. Pradhan, B. Kalantar, M. I. Sameen, M. Santosh, and A. Alamri, "Landslide susceptibility modeling: an integrated novel method based on machine learning feature transformation," Remote Sensing, vol. 13, no. 16, p. 3281, 2021.

[54] R. Al-ruzouq, A. Shanableh, T. Merabtene, and M. Siddique, "Catena potential groundwater zone mapping based on geohydrological considerations and multi-criteria spatial analysis : North UAE," Catena, vol. 173, pp. 511-524, 2019.

[55] R. Al-ruzouq, A. Shanableh, T. Merabtene et al., "Potential groundwater zone mapping based on geo-hydrological considerations and multi-criteria spatial analysis: North UAE," Catena, vol. 173, pp. 511-524, 2019.

[56] M. Alizadeh, E. Alizadeh, S. A. Kotenaee, and H. Shahabi, "Social vulnerability assessment using artificial neural network (ANN) model for earthquake hazard in Tabriz city, Iran," Sustainability, vol. 10, no. 10, p. 3376, 2018.

[57] R. Jena and B. Pradhan, "Integrated ANN-cross-validation and AHP-TOPSIS model to improve earthquake risk assessment," International Journal of Disaster Risk Reduction, vol. 50, p. 101723, 2020.

[58] B. Kalantar, N. Ueda, U. S. Lay, H. A. H. Al-Najjar, and A. A. Halin, "Conditioning factors determination for landslide susceptibility mapping using support vector machine learning," in IGARSS 2019 - 2019 IEEE International Geoscience and Remote Sensing Symposium, pp. 9626-9629, Japan, 2019.

[59] B. Kalantar, B. Pradhan, S. Amir Naghibi, A. Motevalli, and S. Mansor, "Assessment of the effects of training data selection on the landslide susceptibility mapping: a comparison between support vector machine (SVM), logistic regression (LR) and artificial neural networks (ANN)," Geomatics, Natural Hazards and Risk, vol. 9, no. 1, pp. 49-69, 2018.

[60] A. J. Myles, R. N. Feudale, Y. Liu, N. A. Woody, and S. D. Brown, "An introduction to decision tree modeling," Journal of Chemometrics, vol. 18, no. 6, pp. 275-285, 2004.

[61] B. Kalantar, N. Ueda, H. A. H. Al-Najjar, M. B. A. Gibril, U. S. Lay, and A. Motevalli, "An evaluation of landslide susceptibility mapping using remote sensing data and machine learning algorithms in Iran," ISPRS Annals of the Photogrammetry, Remote Sensing and Spatial Information Sciences, vol. 4, no. 2/W5, pp. 503-511, 2019.

[62] G. Biau and E. Scornet, “A random forest guided tour,” TEST, vol. 25, no. 2, pp. 197-227, 2016. 
[63] X. Fan, G. Scaringi, K. Oliver, A. Joshua, and G. Evans, "Earthquake-induced chains of geologic hazards: patterns, mechanisms, and impacts," Reviews of Geophysics, vol. 57, no. 2, pp. 421-503, 2019.

[64] M. Karpouza, K. Chousianitis, G. D. Bathrellos, H. D. Skilodimou, G. Kaviris, and A. Antonarakou, Hazard Zonation Mapping of Earthquake-Induced Secondary Effects Using Spatial Multi-Criteria Analysis, no. 0123456789, Springer, Netherlands, 2021. 